\title{
Free Choice Free Relative Clauses in Italian and Romanian
}

\author{
IVANO CAPONIGRO \\ University of California San Diego \\ ivano@ucsd.edu
}

\author{
ANAMARIA FĂLĂUŞ \\ Laboratoire de Linguistique de Nantes \\ anamaria.falaus@univ-nantes.fr
}

August 16, 2017

\begin{abstract}
This paper aims to bring back to the linguistic scene a largely neglected character that is encountered in Italian and Romanian. This character exhibits a novel combination of morphological, syntactic, semantic, and pragmatic features that, separately, are already attested across languages. It looks like an embedded non-interrogative wh-clause introduced by a wh-phrase that is either made of or contains a wh-root with an affix: the suffix -unque in Italian or the prefix ori-in Romanian. We show that this construction exhibits the same morpho-syntactic properties as -ever free relative clauses in English and the same semantic and pragmatic properties as headed relative clauses introduced by the free choice determiner any in English. Therefore, we label our character a free choice free relative clause. We argue for a syntactic analysis of free choice free relative clauses as true free relatives rather than headed relatives and for a semantic analysis along the lines of some recent proposals about related free choice constructions. We also discuss the meaning of wh-words occurring in free choice free relatives and in related constructions and emphasize the importance of not taking for granted that morpho-syntactic identity necessarily coincides with semantic and pragmatic identity across languages.
\end{abstract}

We investigate a linguistic character in Italian and Romanian that has been largely neglected. It exhibits a novel combination of morphological, syntactic, semantic, and pragmatic features that, separately, are already attested across languages. On the surface, our character looks like an embedded non-interrogative wh-clause introduced by a whphrase that is either made of or contains a wh-root with an affix: the suffix -unque in Italian or the prefix ori- in Romanian. The bracketed strings in (1) and (2) show instantiations of our character in Italian and Romanian, respectively. ${ }^{1}$

(1)
Elena detesta
Elena hates
[ chi-unque la who-FC
'Elena hates anybody that criticizes her.'

Italian (It)

Romanian (Ro)

Elena hates ACC FC-who her criticizes

'Elena hates anybody that criticizes her.'

\footnotetext{
${ }^{1}$ Morpheme boundaries within wh-words are shown in examples (1)-(15) and omitted in subsequent examples, as in standard Italian and Romanian orthography. Tense, mood, person, and number were not glossed, if they could be conveyed with the English gloss. The following abbreviations were used in the glosses: 1: first person; 2: second person; 3: third person; ACC: accusative; CL: clitic; CND: conditional; DAT: dative; FC: free choice; FEM: feminine; GEN: genitive; IMPF: imperfect; IMP: imperative; IND: indicative; PL: plural; REFL: reflexive; REL: relative marker; SBJ: subjunctive; SG: singular. SBJ followed by no tense marking means 'present subjunctive'.
} 
Despite the clausal nature of our character, its distribution is close to that of non-clausal constituents like nominal, prepositional, adjectival, and adverbial phrases. This property, together with the fronted wh-phrase and the corresponding gap, makes our character syntactically resemble a better known construction that is attested in both Italian and Romanian: plain free relative clauses. Compare the plain free relatives in (3) and (4) below with the instantiations of our character in (1) and (2) above. The main morpho-syntactic difference is that the free relative clauses in (3) and (4) are introduced by plain wh-words (like wh-interrogative clauses), without any morphological enrichment:

$\begin{array}{ll}\text { Elena detesta [ chi la critica]. } & \text { Italian (It) } \\ \text { Elena hates who her criticizes } & \\ \text { 'Elena hates the one/those who criticize(s) her.' }\end{array}$
Elena detestă [ pe cine o critică].
Romanian (Ro)
Elena hates ACC who her criticizes
'Elena hates the one/those who criticize(s) her.'

Semantically, our construction carves out its own specific space among the free choice (FC) landscape in Italian and Romanian, as we discuss in depth later. This is why we decided to call it a free choice free relative clause (FC-FR). This label was introduced in Giannakidou and Cheng (2006) for a wh-construction in Greek that exhibits different semantic properties from our FC-FRs. ${ }^{2}$ They argue that their construction is morphosyntactically and semantically equivalent to -ever free relative clauses (ever-FRs) in English. As we discuss at length later in our paper, FC-FRs in Italian and Romanian are semantically different from ever-FRs in English.

FC-FRs as such are absent in English, but their main features are split between two well-known English characters: the morpho-syntactic make-up of FC-FRs is essentially the same as ever-FRs, while the semantic and pragmatic behavior of FC-FRs resembles that of headed relative clauses introduced by the free choice determiner any (FC-any HRs). FC-FRs may, therefore, provide crosslinguistic support to recent attempts to develop an analysis of ever-FRs and FC-any HRs that brings them closer (Aloni 2007b, Dayal 2013b).

FC-FRs in Italian and Romanian have been largely neglected in the literature, with only a few studies addressing this construction. As an anonymous reviewer pointed out, Battye (1989) discusses a number of syntactic properties distinguishing plain free relatives from FC-FRs (which he calls "pseudo-free relatives") in Italian. Grosu (2013) provides an insightful description of the main morpho-syntactic and semantic properties of FC-FRs in Romanian, in parallel with plain free relatives. In addition, previous work on FC in Italian and Romanian had discussed a related construction, namely those DPs formed by a wh-Determiner with the FC morpheme (qual-unque 'which-FC' in Italian; ori-care 'FCwhich' and ori-ce 'FC-what' in Romanian) that do not undergo wh-movement and do not introduce a FC-FR (e.g., Farkas 2002, 2006, Aloni 2007b, Chierchia 2013). Our investigation builds on these earlier studies to further broaden the landscape of FC constructions in both languages. Our findings and proposed account also offer a possible diachronic explanation for the source of those FC DPs with a wh-Determiner.

We chose to conduct a parallel investigation of FC-FRs in Italian and Romanian not only because they have received little attention so far, but also, and more crucially, in order to show that FC-FRs are not just an idiosyncrasy of a single language but emerge from a

\footnotetext{
${ }^{2}$ For instance, the examples of free choice free relatives in (41e), (49a), (65), and (66) in Giannakidou and Cheng (2006) illustrate their core semantic properties and are given as fully acceptable. The morpho-syntactic equivalent FC-FRs in Italian and Romanian are completely unacceptable.
} 
principled clustering of shared morpho-syntactic features. At the same time, the close comparison of Italian and Romanian allows us to discover possible dimensions of variation, i.e. the different historical source of the morphological enrichment of FC wh-words and the different productivity of bare wh-words that can undergo such morphological enrichment, as we discuss further in the first paragraph in Section 1.

We study FC-FRs in Italian and Romanian by comparing them closely with ever-FRs and FC-any HRs in order to highlight further crosslinguistic variation in the complex interplay between morpho-syntactic objects and meanings. We hope that the comparative methodology we employ here may be of help for further investigation of FC-FRs and related constructions across languages.

Finally, FC-FRs support broader considerations on the intralinguistic and crosslinguistic mechanisms that extend the use of wh-words and wh-clauses from interrogative clauses to other wh-constructions like FC-FRs themselves, but also headed relative clauses, plain free relative clauses, and ever-FRs.

The paper is structured as follows. In the next section, we introduce FC-FRs. In Section 2, we suggest a morpho-syntactic analysis and support it by investigating two main features of FC-FRs: (i) the variety of wh-words introducing them and their relation to wh-words introducing wh-interrogative clauses, plain free relative clauses, and headed relative clauses in Italian, Romanian, and English; (ii) the arguments in favor of the claim that FC-FRs are syntactically free relative clauses rather than headed relative clauses. Section 3 deals with semantic and pragmatic properties of FC-FRs. We first show that FCFRs trigger modal inferences and exhibit semantic/pragmatic restrictions that make them very similar to FC-any HRs and different from ever-FRs. Next, we show that FC-FRs and FC-any HRs are sensitive to restrictions that have not been noticed in previous work on FC any that we generalize with a new "Constraint on Acquaintance". In Section 4, we propose a semantic analysis of FC-FRs that is based on recent insights and proposals for FC in general and FC-any HRs and related constructions in particular. In doing so, we discuss previous studies of related but different FC constructions in Italian and Romanian. Finally, we highlight how the different meanings of wh-words in different constructions may be related in a principled way. Section 5 concludes with some broader remarks.

\section{INTRODUCING FC-FRS}

FC-FRs are embedded non-interrogative wh-clauses introduced by FC wh-words/phrases containing a wh-root with the suffix -unque in Italian and the prefix ori-in Romanian. The suffix -unque is not attested anywhere else in Italian and is a direct loan from the corresponding FC wh-expressions in Latin (-cumque). The prefix ori- in Romanian, instead, has a very different source. It functions as a disjunctive marker when used as an independent word rather than an affix. ${ }^{3}$ Almost all Romanian wh-words occurring in interrogative clauses can take the prefix ori- and form FC wh-words introducing FC-FRs, the only exception being the compound form de ce (lit. 'of what') - the equivalent of why.

\footnotetext{
${ }^{3}$ Historically, ori comes from the Latin form uelis $>$ veri / ori ('you.SG want'). It was used as a (correlative) disjunction of the type 'either...or' in Old Romanian. Diachronic studies show that the disjunctive use preceded the FC use, with the latter originating in correlative constructions where the complex disjunction connected two (definite) free relatives (see Dinică 2012 and Gheorghe 2014 and references therein).
} 
Italian, instead, only has three FC-wh-words introducing FC-FRs: chiunque 'who-FC', qualunque 'what/which-FC' , and dovunque 'where-FC'.

Examples of FC-FRs introduced by chiunque 'who-FC' in Italian and oricine 'FCwho' in Romanian were given in (1) and (2). Examples of FC-FRs introduced by all the other FC wh-words/phrases are given in (5) and (6) for Italian and in (7)-(15) for Romanian; the wh-words/phrases are in bold. ${ }^{5}$
Elena detesta
qual-unque
collega la critichi].
Elena hates which-FC colleague her critize.SBJ.SG
'Elena hates any colleague that criticizes her.'

It

Elena va [ dov-unque vada Bianca].

It

Elena goes where-FC go.SBJ.SG Bianca

'Elena goes to any places Bianca goes to.'

(7) Elena detestă [ ori-ce coleg o critică ].

Ro

Elena hates $\quad F C$-what colleague her criticizes

'Elena hates any colleague that criticizes her.'

(8) Elena merge la [ ori-care/ ori-ce petrecere merge Bianca ]. Ro Elena goes to FC-which/FC-what party goes Bianca 'Elena goes to any party Bianca goes.'

(9) Aş merge [ori-unde mergi tu].

would.1SG go FC-where go.2sG you

'I would go any places you go.'

(10) Voi pleca [ ori-când vei pleca tu].

Ro

will.1SG leave FC-when will.2SG leave you

'I'll leave any time you leave.'

(11) Mănânc [ori-cum mănânci tu].

Ro

eat.1SG FC-how eat.2SG you

'I eat in any way you do it.'

(12) Voi

$\begin{array}{llll}\text { Voi mânca [ ori-cât vei mânca tu] } & \\ \text { will.1sG eat } & \text { FC-how much will.2sG } & \text { eat you }\end{array}$

'I will eat any you will eat.'

(13) Pot

conduce [ ori-cât de repede conduci tu].

can.1SG drive FC-how of fast drive.2SG you

'I can drive at any speed you drive.'

\footnotetext{
${ }^{4}$ Comunque, which is morphologically made of come 'how' and -unque, can only be used as an adverbial meaning 'in any case'/'anyhow' or a clausal subordinator meaning 'no matter how' or 'nevertheless'. Quandunque, which is morphologically made of quando 'when' and -unque, used to introduce FC-FRs in Old Italian but is no longer part of the active lexicon. Qualsiasi is used with the same distribution and interpretation as qualunque; the suffix -siasi is not used in any other FC expression.

${ }^{5}$ FC-FRs in Italian always allow for subjunctive (and strongly favor it in the variety spoken by one of the authors). In Romanian, subjunctive is not allowed in FC-FRs (cf. Farkas 1985 for subjunctive in Romanian and Italian with special focus on its use in headed relative clauses and Farkas 1992 for the distribution of subjunctive in complement clauses in Romanian). Instead, another non-indicative mood - the conditional is possible in FC-FRs in Romanian, with no clear preference for either the indicative and conditional mood (e.g., the sentences in (18)-(20) below).
} 
(14) Pot fi [ori-cât de zgomotos poți fi şi tu].

Ro can.1SG be FC-how of loud can.2SG be also you 'I can be loud at any level you can be.'

(15) Pot corecta [ori-câte lucrări vrei]. Ro can.1SG correct FC-how_many.FEM.PL paper.FEM.PL want.2sG 'I can grade any number of papers you want.'

As the examples above show, FC-FRs can occur in a variety of syntactic environments with a distribution resembling that of DPs, PPs, AdjPs, or AdvPs. For instance, in the Italian example in (16), the bracketed FC-FR can be replaced by the bracketed complex DP containing a headed relative clause in the complement position of the main predicate.

(16) Elena detesta [ chiunque la critichi]/ [DP le persone che la criticano]. It Elena hates who-FC her criticize.SBJ.SG/ the people that her criticize.3PL 'Elena hates \{anybody that criticizes her\}/\{the people that criticize her\}.'

Similarly, in the Romanian example in (17), the bracketed FC-FR can be replaced by the bracketed AdjP.

(17) Pot fi [ oricât de ${ }^{6}$ zgomotos poți fi şi tu]/[Adjp foarte zgomotos]. Ro can.1SG be FC-how of loud can.2SG be alsoyou/ very loud 'I can be $\{$ loud at any level you can $\} /\{$ very loud $\}$.'

In general, the distribution of FC-FRs depends on the syntactic nature of the FC-wh-word/phrase introducing them, as can be detected by looking at the trace/gap the FC-wh-word/phrase licenses. For instance, the FC wh-word chiunque in (16) above behaves like a DP since it licenses a DP gap/trace in the subject position of the embedded predicate; therefore, the whole FC-FR behaves like a DP. Similarly, the FC wh-phrase oricât de zgomotos in (17) above behaves like an AdjP since it licenses a gap/trace in the complement of the copula in the FC-FR; therefore, the whole FC-FR behaves like an AdjP.

A construction that looks like a FC-FR can occur at either edge of the main clause with or without direct linkage to the main clause via a pronominal element, both in Italian and Romanian. The bracketed strings in (18) show examples of FC-FRs in the object position of the matrix predicate. In (19), identical bracketed strings are left dislocated with the interpretative option of binding the object clitic — la in Italian and $o$ in Romanian - in the matrix clause. Finally, in (20) identical bracketed strings are right dislocated without any overt link with the matrix clause.
a. Rifiutano [ qualunque proposta faccia Elena].
It 'They reject any proposal Elena comes up with.'
b. Refuză [orice propunere (ar) face Elena] reject.3PL FC-what proposal CND.3SG make Elena
'They reject any proposal Elena would come up/comes up with.'

\footnotetext{
${ }^{6}$ The element $d e$ is multifunctional in Romanian: it can be a preposition or a case marker, or can appear in various quantity expressions. In the AdjPs or AdvPs we are considering in this paper, de has been analyzed as the head of a DegP, a syntactic detail that we will ignore in our analysis of FC-FRs (see Cornilescu and Giurgea 2013 for a detailed discussion of de-constructions in Romanian).
} 
(19)

a. [ Qualunque proposta faccia Elena], la rifiutano.

It which-FC proposal make.SBJ.SG Elena it.ACC reject.3PL 'No matter what proposal Elena comes up with, they reject it.'

b. [ Orice propunere (ar) face Elena], o refuză.

Ro FC-what proposal CND.3SG make Elena her.ACC reject.3PL 'No matter what proposal Elena would come up/comes up with, they reject it.'
a. Non cambio
idea, [ qualunque proposta faccia
Elena].
It not change.1SG idea which-FC proposal make.SBJ.SG Elena
'I won't change my mind, no matter what proposal Elena comes up with.'
b. Nu-mi schimb părerea, [orice propunere (ar) face Elena].Ro
not-my.DAT change.1SG opinion FC-what proposal CND.3SG make Elena
'I won't change my mind, no matter what proposal Elena would come up/comes up with.'

Although identical on the surface and intuitively related in meaning, the bracketed strings in (18), (19), and (20) occur in different syntactic positions and are linked to the matrix clause in different ways. Therefore, their semantic composition cannot be the same as for FC-FRs. Specifically, we feel that the semantic contribution of (19), even under the bound interpretation of the pronoun, is not the same as (18), as highlighted by the different translations. The semantic contribution of (20) (or (19) when the pronoun is not bound) is clearly different from that of FC-FRs: the bracketed wh-clause acts like a clausal adjunct rather than an argument. In the remainder of the paper, we focus on FC-FRs like the one in (18) and leave the dislocated constructions in (19) and (20) for future investigation. ${ }^{7}$

\section{THE MORPHO-SYNTACTIC NATURE OF FC-FRS}

In this section, we argue that FC-FRs in Italian and Romanian, like ever-FRs in English, are morpho-syntactically akin to plain free relatives, rather than headed relatives (Section 2.1). We support this claim by showing that the words or phrases introducing FC-FRs are morphologically built out of the same set of wh-words introducing plain free relatives and constituent interrogatives (Section 2.2) and that relative markers that can or must occur with headed relatives cannot occur with FC-FRs (Section 2.3).

\subsection{The syntactic structure of FC-FRs}

The syntax of ever-FRs, and free relatives in general, has been under discussion for at least 40 years and the debate is still quite open (cf. overview in van Riemsdijk 2006). The two main and related issues have been (i) whether FRs are simple wh-clauses (CPs) or are larger structures with their CP embedded within a head, like headed relatives, and (ii) if FRs have a head, whether the wh-words/phrases introducing FRs move within the CP boundaries (and the head is therefore silent) or move further to the head position, or are directly basegenerated in that position. As we will show in the next two sections, FC-FRs exhibit clear

\footnotetext{
${ }^{7}$ English exhibits a similar tripartite pattern with ever-wh-clauses, as shown in (i)-(iii). The literature on ever-FRs (cf. Jacobson 1995, Dayal 1997, von Fintel 2000, Condoravdi 2015 a.o.) has focused on (i). The few investigations of the construction in (iii) have treated it as substantially different from ever-FRs, more like a clausal adjunct with a conditional import (cf. Izvorski 2000, Rawlins 2013). The construction in (ii) has been virtually ignored. See Section 4.4 and Section 5 for further remarks on ever-FRs.

(i) They reject [whatever proposals Julie comes up with].

(ii) [Whatever proposal Julie comes up with], they reject it.

(iii) [Whatever proposal Julie comes up with], I won't change my mind.

This similarity between ever-FRs and FC-FRs may be taken as further evidence of their syntactic resemblance.
} 
differences with respect to headed relatives. Therefore, had they had a head, something different and special needs to be said in order to keep them separate from standard headed relatives. For the sake of simplicity and in line with previous work on the syntax/semantics of free relatives in general (cf. Caponigro 2003, 2004), we assume in the remainder of the paper that FC-FRs (and ever-FRs) are simple wh-clauses with nothing above their CP layer as in (21)a, although nothing crucial hinges on this assumption. The label $w h-F C_{l}$ in the specifier of CP in (21)a stands for the moved wh-word/phrase introducing a FC-FR in Italian and Romanian, wh-ever $_{l}$ for the wh-word/phrase introducing an ever-FR in English, and $w_{-I}$ for the wh-word/phrase introducing a plain free relative in each of the three languages. Headed relative clauses in general, instead, will have the usual structure given in (21)b. (For convenience, we assume that the operator $\mathrm{Op}_{1}$ binding the trace $t_{1}$ and the relative marker REL are two distinct syntactic elements, though nothing crucial hinges on this assumption). This is also the structure that we assume for FC-any HRs, a subset of headed relative clauses that will be particularly relevant for the semantic discussion in Section 3.

(21) a. The syntactic structure of FC-FRs, ever-FRs, and plain free relatives:

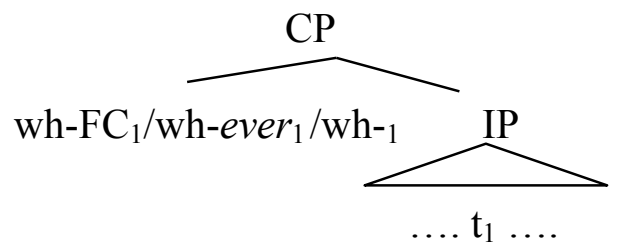

b. The syntactic structure of FC-any HRs and headed relative clauses in general:

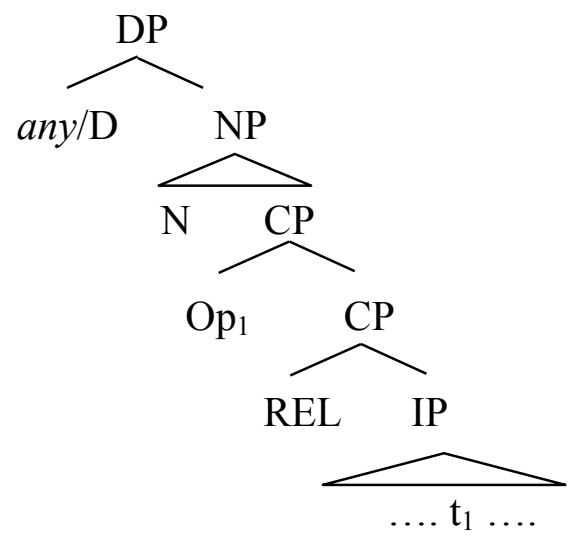

An anonymous reviewer invited us to consider a different syntactic analysis of FC-FRs, along the line of Donati and Cecchetto (2011: Appendix, pp. 552-557). These authors argue that what we labelled FC-FRs are actually headed relative clauses, reformulating a claim in Battye (1989). They support their proposal with the three main differences between plain free relatives and FC-FRs that Battye (1989: 225-231) highlights. One of these differences has to do with the fact that FC-FRs can allegedly be followed by complementizers and relative markers in Italian. In Section 2.3 (fn. 12), we take issue with this claim, at least for the variety of Italian we are investigating, and provide further evidence in support of our analysis. A second difference mentioned in Battye (1989: 227-228) has to do with an alleged subtle contrast between degrees of unacceptability in gapping data (* vs. ??), which Rizzi (1984:30-33) does not share, nor do we. The last difference is about the fact that FC wh-words can be used in situ independently, while bare wh-words cannot (cf. (22)-(26) 
below and related discussion); we believe that the explanation of this contrast lies in the different semantic properties of the two classes of items, as we discuss later in Section 4.4. We therefore conclude that our proposal in (21)a to treat FC-FRs syntactically as the same plain free relative clauses, rather than headed relative clauses, is not challenged by Battye (1989) or Donati and Cecchetto (2011). The next two sections will bring further evidence in support of our proposal.

\subsection{Wh-words introducing FC-FRs and related constructions}

In order to understand the syntactic structure we are proposing for FC-FRs and to better situate them, it may be useful to consider a more general picture of the relation between wh-words and (different kinds of) relative clauses in Italian and Romanian. As mentioned in Section 1, almost all the wh-words that can occur in interrogatives can be prefixed with ori- and occur in Romanian FC-FRs, while in Italian the number of wh-words that can be suffixed with -unque and introduce FC-FRs is more restricted (chiunque 'who-FC', dovunque 'where-FC', qualunque 'which-FC').

Plain free relatives exhibit a similar productivity difference between the two languages. In Romanian, all wh-words can introduce plain free relatives, including de ce 'why', while in Italian only four phrasal wh-words — wh-words forming a whole phrase by themselves without any further lexical material—can introduce standard FRs: chi 'who', dove 'where', quando 'when', and come 'how'.

Finally, headed relatives are introduced by a smaller number of wh-words: five in Romanian (all the phrasal wh-words but cine 'who' and de ce 'why') and only one in Italian (dove 'when'). ${ }^{\text {' }}$

For comparison with a more familiar language, English positions itself in between Romanian and Italian with respect to the productivity of transfer of wh-words into their free relative and headed relative uses. Like Romanian, all English wh-words can be morphologically enriched (by the suffix -ever) and introduce ever-FRs, except for why. Like Italian, only phrasal wh-words can introduce plain free relatives in English. ${ }^{10}$ Three wh-words can introduce headed relative clauses productively in English (who, where, and when), instead of five in Romanian and only one in Italian.

Tables 1 and 2 below provide the full inventory of wh-words in interrogative clauses in Italian, Romanian, and English, and show which of those wh-words occur in plain free relatives and/or FC-FRs. Table 1 groups the languages by wh-construction in order to more easily show which wh-words can occur in the same constructions crosslinguistically. Table 2 groups the wh-constructions by language highlighting which wh-words can occur in multiple constructions within the same language.

\footnotetext{
${ }^{8}$ Complex wh-phrases_-phrases containing a wh-word and other lexical material—cannot introduce plain free relatives in Italian. The equivalent of what is the complex wh-phrase che cosa (lit. 'what thing'), which, cannot introduce plain free relatives. There is no -unque from che cosa, but qualunque cosa is used, instead. ${ }^{9}$ Romanian allows for the wh-word cât/câtă/câți/câte 'how much/many' (inflected by gender and number) to introduce headed relative clauses whose nominal head is preceded by a numeral or certain quantifiers (Grosu 2013). Cât/câtă/câți/câte in headed relative clauses does not select for any other lexical material, while it selects for an NP, an AdjP, or an AdvP in FC-FRs, plain free relative clauses, and wh-interrogative clauses. As an anonymous reviewer reminded us, Italian can use the wh-word quale/quali 'which'(inflected by number) preceded by the definite determiner to introduce appositive relative clauses (if the subject or the object are relativized) or restrictive relative clauses (if any other constituent is relativized). Either use is marked as high-register. The form definite determiner + quale/quali is not allowed in any other construction. ${ }^{10}$ Plain free relative clauses introduced by who in English exhibit various degrees of acceptability (cf. Patterson and Caponigro 2016), while the corresponding chi FRs in Italian are fully productive.
} 
Table 1. List of wh-words occurring in interrogative clauses in English (En), Italian (It), and Romanian (Ro), and their occurrence in three other constructions: plain free relatives (FR), FC-FRs in Italian and Romanian and ever-FRs in English (xFR), and headed relatives (HR). Languages are grouped by construction.

\begin{tabular}{|l|c|c|c|c|c|c|c|c|c|}
\hline Wh-words in Interrogatives & \multicolumn{3}{|c|}{ FR } & \multicolumn{3}{c|}{ xFR } & \multicolumn{3}{c|}{ HR } \\
\hline & En & It & Ro & En & It & Ro & En & It & Ro \\
\hline Who $($ chi, cine) & $?$ & $\sqrt{ }$ & $\sqrt{ }$ & $\sqrt{ }$ & $\sqrt{ }$ & $\sqrt{ }$ & $\sqrt{ }$ & $*$ & $*$ \\
\hline What $($ che cosa, ce) & $\sqrt{ }$ & $*$ & $\sqrt{ }$ & $\sqrt{ }$ & $*$ & $\sqrt{ }$ & $*$ & $*$ & $\sqrt{ }$ \\
\hline When (quando, când) & $\sqrt{ }$ & $\sqrt{ }$ & $\sqrt{ }$ & $\sqrt{ }$ & $*$ & $\sqrt{ }$ & $\sqrt{ }$ & $*$ & $\sqrt{ }$ \\
\hline Where (dove, unde) & $\sqrt{ }$ & $\sqrt{ }$ & $\sqrt{ }$ & $\sqrt{ }$ & $\sqrt{ }$ & $\sqrt{ }$ & $\sqrt{ }$ & $\sqrt{ }$ & $\sqrt{ }$ \\
\hline How (come, cum) & $\sqrt{ }$ & $\sqrt{ }$ & $\sqrt{ }$ & $\sqrt{ }$ & $*$ & $\sqrt{ }$ & $*$ & $*$ & $\sqrt{ }$ \\
\hline Why (perché, de ce) & $*$ & $*$ & $\sqrt{ }$ & $*$ & $*$ & $*$ & $?$ & $*$ & $*$ \\
\hline What + NP $($ che, ce) & $*$ & $*$ & $\sqrt{ }$ & $\sqrt{ }$ & $*$ & $\sqrt{ }$ & $*$ & $*$ & $*$ \\
\hline Which + NP $($ quale, care) & $*$ & $*$ & $*$ & $\sqrt{ }$ & $\sqrt{ }$ & $\sqrt{ }$ & $*$ & $*$ & $*$ \\
\hline How much (quanto, cât) & $*$ & $*$ & $\sqrt{ }$ & $\sqrt{ }$ & $*$ & $\sqrt{ }$ & $*$ & $*$ & $\sqrt{ }$ \\
\hline $\begin{array}{l}\text { How much/many + NP/AdjP/AdvP } \\
\text { (quanto/quanti, cât/câtă/câți/câte) }\end{array}$ & $*$ & $*$ & $\sqrt{ }$ & $\sqrt{ }$ & $*$ & $\sqrt{ }$ & $*$ & $*$ & $*$ \\
\hline
\end{tabular}

Table 2. List of wh-words occurring in interrogative clauses in English (En), Italian (It), and their occurrence in three other constructions: plain free relatives (FR), FC-FRs in Italian and Romanian and ever-FRs in English (xFR), and headed relatives (HR). Constructions are grouped by language.

\begin{tabular}{|c|c|c|c|c|c|c|c|c|c|}
\hline \multirow[t]{2}{*}{ Wh-words in Interrogatives } & \multicolumn{3}{|c|}{ English } & \multicolumn{3}{|c|}{ Italian } & \multicolumn{3}{|c|}{ Romanian } \\
\hline & FR & xFR & HR & FR & xFR & HR & FR & xFR & HR \\
\hline Who (chi, cine) & $?$ & $\sqrt{ }$ & $\sqrt{ }$ & $\sqrt{ }$ & $\sqrt{ }$ & * & $\sqrt{ }$ & $\sqrt{ }$ & * \\
\hline What (che cosa, ce) & $\sqrt{ }$ & $\sqrt{ }$ & $*$ & $*$ & $*$ & $*$ & $\sqrt{ }$ & $\sqrt{ }$ & $\sqrt{ }$ \\
\hline When (quando, când) & $\sqrt{ }$ & $\sqrt{ }$ & $\sqrt{ }$ & $\sqrt{ }$ & $*$ & $*$ & $\sqrt{ }$ & $\sqrt{ }$ & $\sqrt{ }$ \\
\hline Where (dove, unde) & $\sqrt{ }$ & $\sqrt{ }$ & $\sqrt{ }$ & $\sqrt{ }$ & $\sqrt{ }$ & $\sqrt{ }$ & $\sqrt{ }$ & $\sqrt{ }$ & $\sqrt{ }$ \\
\hline How (come, cum) & $\sqrt{ }$ & $\sqrt{ }$ & $*$ & $\sqrt{ }$ & $*$ & * & $\sqrt{ }$ & $\sqrt{ }$ & $\sqrt{ }$ \\
\hline Why (perché, de ce) & $*$ & $*$ & $?$ & $*$ & $*$ & * & $\sqrt{ }$ & $*$ & $*$ \\
\hline What + NP $($ che, $c e)$ & $*$ & $\sqrt{ }$ & $*$ & $*$ & $*$ & $*$ & $\sqrt{ }$ & $\sqrt{ }$ & $*$ \\
\hline Which + NP (quale, care) & $*$ & $\sqrt{ }$ & $*$ & $*$ & $\sqrt{ }$ & $*$ & $*$ & $\sqrt{ }$ & $*$ \\
\hline How much (quanto, cât) & $*$ & $\sqrt{ }$ & $*$ & * & $*$ & * & $\sqrt{ }$ & $\sqrt{ }$ & $\sqrt{ }$ \\
\hline $\begin{array}{l}\text { How much/many + NP/AdjP/AdvP } \\
\text { (quanto/quanti, cât/câtă/câți/câte) }\end{array}$ & $*$ & $\sqrt{ }$ & * & * & * & * & $\sqrt{ }$ & $\sqrt{ }$ & * \\
\hline
\end{tabular}

The emerging picture highlights different degrees of transfer of wh-words from their interrogative use to their use in free relatives and headed relatives in Italian, Romanian, and English. The set of wh-words used in FC-FRs or ever-FRs is neither a subset nor a superset of the set of wh-words in plain free relatives. However, the amount of overlapping is much more substantial than with the set of wh-words introducing headed relatives. We view this pattern as more compatible with an analysis of FC-FRs as free relatives.

On the other hand, this pattern also shows that FC-FRs (or ever-FRs) are not simply derived from plain free relatives (and even less from headed relatives) via a syntactic 
mechanism surfacing as an affix on the wh-word. Otherwise, we would expect all and only the wh-words in plain free relatives to undergo morphological enrichment and occur in FCFRs. Instead, FC-FRs are better seen as a possibly related but definitely independent construction from plain free relatives, licensed by the availability of morphologically enriched wh-words in the lexicon, with the idiosyncrasies and restrictions that are common to processes of derivational morphology. This approach makes the prediction that it should be possible to find a language with FC-FRs lacking plain free relatives. Ute, a Uto-Aztecan language spoken in Colorado, could be such a language (Givón 2011 and Tom Givón p.c.).

Finally, our findings indicate that the use of wh-words in non-interrogative whclauses is not the result of an all-or-none mechanism such that if one wh-word occurs in a certain non-interrogative construction then all the others will too. It looks like languages require for each wh-word to be independently licensed in each non-interrogative wh-clause.

All the morphologically enriched wh-words or wh-phrases that can introduce FCFRs in Italian and Romanian can also occur in situ as FC items on their own, without introducing FC-FRs. On the other hand, no plain wh-word or wh-phrase can ever occur in situ in a non-interrogative construction in Italian or Romanian (cf. Battye 1989 for Italian). English exhibits a similar pattern. Examples from Italian and Romanian are given in (22)-(26) below with wh-words in bold. The English translations provide equivalent examples for English.

(22) Luca parla con chiunque/*chi.

It

Luca speaks with who-FC / who

'Luca speaks to anybody/*who.' (cf. Luca speaks to whoever.)

(23) Posso dormire dovunque/*dove.

can.1SG sleep where-FC / where

'I can sleep anywhere/*where.' (cf. I can sleep wherever.)

(24) Sono pronto ad accettare \{qualunque/*quale\} sfida.

It

am ready to accept which-FC/ which challenge

'I'm ready to take on any/*which challenge.'

(cf. I'm ready to take on whatever challenge.)

(25) Din partea lui, mă pot aștepta la orice. /*ce

Ro

from part his me can expect.1SG at FC-what/ what

'I can expect anything/*what from him.'

(cf. I can expect whatever (surprise) from him.)

(26) Ca să plece, i-aş

fi dat oricât

/*ât.

Ro

to SBJ leave CL.3SG-would.1SG be given FC-how_much/ how_much

'To have him/her leave, I would have given no matter how much/*how much.'

(cf. I would have given him/her however much—just to have him/her leave.)

A brief and non-systematic diachronic look at FC-FRs in Italian and Romanian shows that this independent use of FC wh-words is a later development: all earlier examples show FC wh-words introducing full FC-FRs; the same pattern is observed with -ever wh-words in English. ${ }^{11}$ In Section 4.4, we will show how independent FC wh-words can be derived from those introducing FC-FRs in a systematic and principled way.

\footnotetext{
${ }^{11}$ Thanks to the anonymous reviewer that first pointed out these diachronic facts for a related construction in Dutch (e.g., wie dan ook 'who then also'); cf. Aguilar et al (2010) for further details. For Italian, our search was conducted on Tommaseo Online (http://www.tommaseobellini.it) and Lessicografia della Crusca in Rete (http://www.lessicografia.it/) on November 15, 2016. For Romanian, we rely on Dinică (2012), Gheorghe
} 


\subsection{Lack of a head and a relative marker in FC-FRs}

In this section, we present further evidence against an analysis of FC-FRs as headed relative clauses. Specifically, we show that like plain free relative clauses, FC-FRs lack the core syntactic features of headed relative clauses in Italian and Romanian-a constituent acting as the head and an obligatory relative marker.

Headed relative clauses in both Italian and Romanian must be introduced by a relative marker (REL) obligatorily occurring between the head and the remainder of the relative clause. The Italian relative marker is derived from a Latin wh-word that no longer functions as a wh-word in any other construction; the Romanian relative marker, instead, is identical to the wh-word care 'which'.

(27) Elena va nei [posti *(in cui) va Bianca]. It Elena goes to-the places in REL goes Bianca

'Elena goes to the places Bianca goes to.'

(28) Elenamerge în [locurile *(în care) merge Bianca]. Ro Elenagoes in places-the in REL goes Bianca

'Elena goes to the places Bianca goes to.'

Whenever the subject or direct object is relativized in Italian, the declarative complementizer che 'that' must be used as the relative marker, as shown in (29):

(29)

Elena detesta [le persone *(che) apprezzano Bianca]. It

Elena hates the people REL appreciate.3PL Bianca

'Elena hates the people that appreciate Bianca.'

Those relative markers (or complementizers) cannot occur in plain free relatives:

(30) Elena va [dove (*in cui) va Bianca].

It

Elena goes where in REL goes Bianca

'Elena goes where Bianca goes.'

(31) Elena merge [unde (*în care) merge Bianca]. Ro

Elena goes where in REL goes Bianca

'Elena goes where Bianca goes.'

FC-FRs behave like plain free relatives as far as relative markers are concerned, i.e., those markers can never introduce FC-FRs:

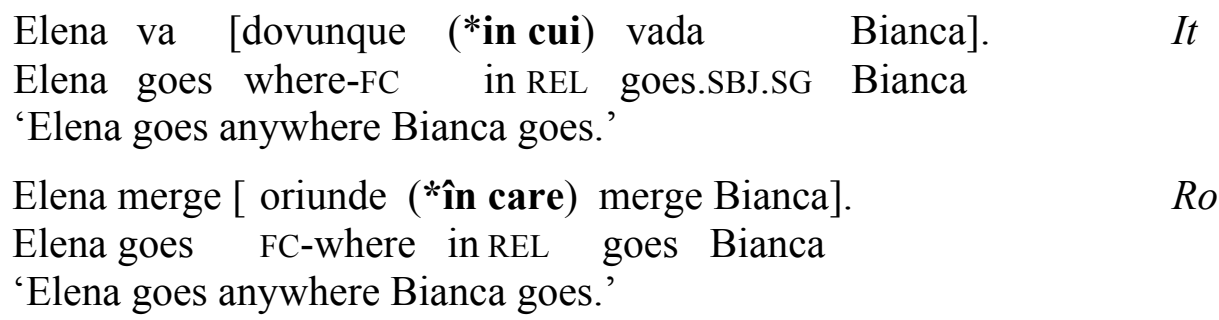

(2014), and Giurgea (2016). For English, we conducted a search on the online version of the Oxford English Dictionary (http://www.oed.com) on November 21, 2016 and searched the Penn Corpus of Historical English (https://www.ling.upenn.edu/hist-corpora/) (many thanks to Gary Patterson for helping us with the latter). 
The declarative complementizer that can introduce headed relative clauses in Italian cannot introduce plain free relatives or FC-FRs either:

Elena detesta [ chi (*che) apprezza Bianca]. It
Elena hates who REL appreciates Bianca
'Elena hates the one/those who \{appreciate(s) Bianca $\} /\{$ Bianca appreciates $\} . '$

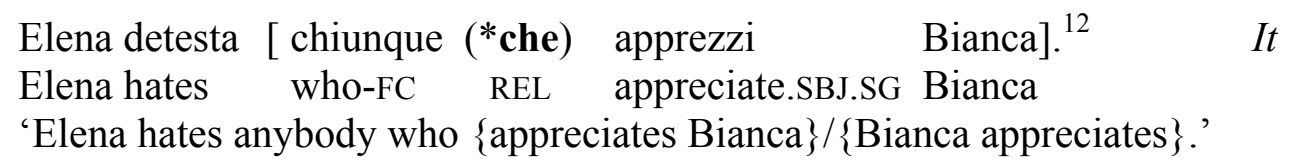

One may wonder if examples like (36) and (37), with a clause headed by a FC wh-phrase, are not counterexamples, indicating that FC-FRs can in fact behave like headed relative clauses and occur with relative markers:

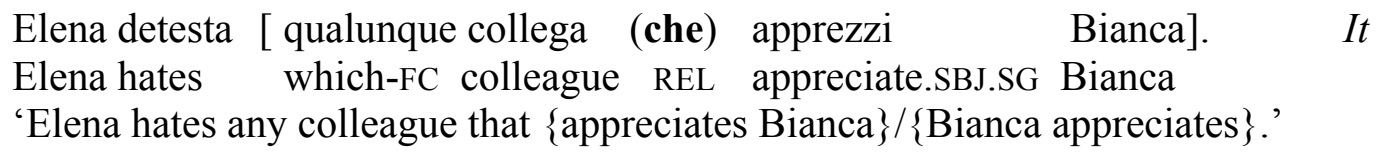
Elena detestă [ orice
coleg (care) o
apreciază pe
Bianca].
Ro
Elena hates FC-which colleague REL her appreciates ACC Bianca
'Elena hates any colleague that appreciates Bianca.'

Note, however, that the FC wh-phrases qualunque collega in (36) and orice coleg in (37) and FC phrasal wh-words like chiunque and oricine can occur by themselves without introducing a FC-FR in Italian and Romanian, as shown in (38)-(39) (see also section 2.2):
Elena detesta $\{$ qualunque collega $\} /$ chiunque.
Elena hates which-FC colleague/who-FC
'Elena hates any colleague/anyone.'

It
Elena detestă \{ orice
coleg
/pe oricine.
Elena hates FC-which colleague/ACC FC-who
'Elena hates any colleague/anyone.'

Therefore, the bracketed clauses in (36) and (37) with a relative marker are headed relative clauses with an independent FC wh-phrase as their head, while the variants without a relative marker are FC-FRs with the FC wh-phrase being part of them, rather than a head. Italian exhibits a further contrast between FC-FRs and headed relative clauses introduced

\footnotetext{
${ }^{12}$ The same anonymous reviewer who invited us to consider a different syntactic analysis of FC-FRs (see discussion at the end of Section 2.1) finds this sentence and similar sentences with a FC-FR introduced by chiunque che degraded but still acceptable, while agreeing with us that sentences with a plain FR introduced by chi che like (34) are unacceptable. The reviewer pointed out that similar judgments are reported in Battye (1989) and suggested that our unacceptability judgments may be prescriptive in nature. Another anonymous reviewer who is also a native speaker of Italian did not mention any disagreement with our Italian judgments. We checked our intuitions with seven more native speakers, who all confirmed our judgments. All our consultants are from Lombardia, a Northern region of Italy. Some of them from areas around Milan, the region capital, some others from areas 100 miles away. Two of them are linguists, the others are nonacademics with high-school or college-level education. We found no substantial differences between the two groups and are not aware of any prescriptive rule having to do with -unque wh-words. Unfortunately, neither the disagreeing reviewer nor Battye (1989) provide details about how many consultants they collected their data from and from which areas of Italy they were. At this point, it is an open issue whether the anonymous reviewer and Battye (1989) are dealing with a variety of Italian different from the one we are investigating.
} 
by the same complex FC-wh-phrase: mood. As shown in (36), subjunctive is allowed in both FC-FRs (without the complementizer che) and headed relative clauses (with the complementizer che). The sentence in (40) below shows that indicative mood (IND) is fully compatible with the headed relative clause, while (41) shows that the indicative mood makes the FC-FR degraded, at least in the variety of Italian spoken by one of the authors (see fn. 5).

(40) Elena detesta [ qualunque collega che apprezza Bianca]. It Elena hates which-FC colleague REL appreciate.IND.3SG Bianca

'Elena hates any colleague that $\{$ appreciate(s) Bianca $\} /\{$ Bianca appreciates $\}$.'
?? Elena detesta [qualunque collega apprezza
Elena hates which-FC colleague appreciate.IND.3SG Bianca
Bianca].
'Elena hates any colleague that $\{$ appreciate(s) Bianca $\} /\{$ Bianca appreciates $\} . '$

In conclusion, we take it that (36) and (37) are not counterexamples to our general claim that FC-FRs are not headed relatives because of the dual status of FC wh-words or phrases: they can introduce FC-FRs or occur by themselves.

Notice that no FC phrasal wh-words can ever be the head of headed relative clauses, as shown in (35) above for chiunque Italian and in (42) below for oricine in Romanian.

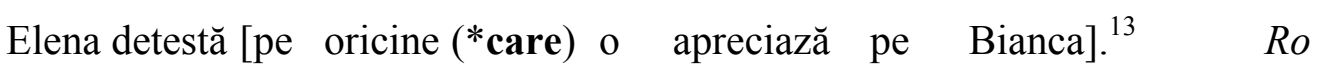
Elena hates ACC FC-who REL her appreciates ACC Bianca 'Elena hates any colleague that appreciates Bianca.'

On the other hand, FC phrasal wh-words can occur by themselves without introducing a FC-FR, as illustrated in (22) above for chiunque and in (43) for oricine.
Elena detestă pe oricine.
Elena hates ACC FC-who
'Elena hates anybody.'

The ban on independent FC phrasal wh-words from being the heads of headed relative clauses probably stems from the fact that FC phrasal wh-words have a syntactic category larger than NPs, which are the kind of phrases headed relative clauses attach to and modify. For instance, chiunque and oricine are formed out of the plain phrasal wh-words chi and cine, which exhibit the same distribution as DPs rather than NPs. The FC wh-phrases qualunque/oricare $+\mathrm{NP}$, instead, contain an NP that can be modified by a headed relative clause. Similar arguments could be constructed for English whichever/whatever + NP. ${ }^{14}$

To sum up, we have argued that FC-FRs and ever-FRs are morpho-syntactically closer to plain free relative clauses than they are to headed relative clauses since they are all non-interrogative wh-clauses without a head. In their independent use, FC wh-phrases qualunque/orice + NP are the only ones introducing headed relative clauses.

\footnotetext{
${ }^{13}$ We found one native speaker for whom the use of care in this construction does not seem entirely ruled out (although the variant without care is still the preferred one). The source of this variation is a matter that we leave for future investigation.

${ }^{14}$ The restriction observed for chiunque and oricine is attested with non-wh expressions as well. For instance, ognuno 'every/each one' and ciascuno 'each one' in Italian are single words with the same distribution as DPs. They cannot be modified by a headed relative clause, as shown in (i).
}
(i) * Elena detesta ognuno/ciascuno (che) apprezza Bianca.
It

Elena hates everyone/each one REL appreciates Bianca 


\section{Semantic Properties of FC-FRs}

In the previous section, we offered evidence that Italian and Romanian FC-FRs closely resemble English ever-FRs in their morpho-syntax. In the following, we show that this uniform morpho-syntactic picture does not map onto similar semantic and pragmatic properties. We first discuss the various modal inferences conveyed by FC-FRs and ever-FRs (Section 3.1) and then focus on previously unnoticed constraints concerning the type of knowledge at play in FC constructions (with both FC-any HRs and FC-FRs).

\subsection{Modal inferences}

Ever-FRs have been analyzed as modalized definite descriptions triggering an inference of ignorance or indifference about the identity of the individual they refer to (Jacobson 1995, Dayal 1997, von Fintel 2000, Condoravdi 2015). FC-FRs, instead, exhibit a different semantic behavior, closely resembling English FC-any HRs.

The sentence in (44)a illustrates a case in which ever-FRs can be used to convey the modal inference of the speaker being ignorant with respect to the identity of the individual the speaker is referring to, i.e., the (atomic or plural) individual who had the access code to the building. The morpho-syntactically equivalent FC-FRs in Italian and Romanian are completely unacceptable in this context, as shown in (44)b-c. If the ever-FR in (44)a is replaced with a FC-any HR as in (44)d, the result is unacceptable as well.

(44) CONTEXT: The speaker is aware that someone broke into the company last night but doesn't know who:

a. It was whoever had the access code to the building, (though I don't know who it was).

b. * ${ }^{\mathrm{E}}$ stato chiunque abbia il codice di accesso all'edificio, It has been who-FC have.SBJ.SG the code of access to-the-building (sebbene non sappia chi sia).

though not know.SBJ.SG who be.SBJ.SG

c. * A fost oricine avea codul de acces al clădirii, (deşi nu Ro has been FC-who had code-the of access of building-the though not ştiu cine a fost). know.1SG who it was.

d. * It was any person who had the access code to the building, (though I don't know who it was).

The unacceptable sentences, with FC-FRs or with FC-any HRs, become acceptable in the very same context if a modal operator, in this case an epistemic modal, is added to the matrix predicate, as shown in bold (45):

(45) a. It could have been whoever had the access code to the building.

b. Può essere stato chiunque abbia il codice di accesso all'edificio. It can.3SG be been who-FC have.SBJ.SG the code of access to-the-building

c. Poate să fi fost oricine avea codul de acces al clădirii. Ro can.3SG SBJ be been FC-who had.3SG code-the of access of building-the

d. It could have been any person who had the access code to the building. 
Not any modal in the matrix clause makes sentences with FC-FRs acceptable. While a possibility modal does, as we just saw, an epistemic necessity modal often does not, as in (46)b-c. In contrast, ever-FRs are felicitous no matter what modal is chosen, as shown in (46)a. Finally, FC-any HRs pattern like FC-FRs in this case as well, as illustrated in (46)d. ${ }^{15}$

(46) a. It must have been whoever had the access code to the building.

b. * Deve essere stato chiunque abbia il codice di accesso It must.3SG be been who-FC have.SBJ.SG the code of access all'edificio. to-the building

c. ${ }^{*}$ Trebuie să fi fost oricine avea codul de acces al clădirii. Ro must.3SG SBJ be been FC-who had.3SG code-the of access of building-the

d. * It must have been any person who had the access code to the building.

Similarly, while the English sentence in (47)a (adapted from Dayal 1997) is perfectly acceptable, its equivalents in Italian and Romanian are ruled out, even if speaker ignorance is clearly indicated (47)b-c. Once again, FC-any HRs pattern like FC-FRs (47)d.

(47) CONTEXT: The speaker can see that Bianca is cooking three dishes now. She doesn't know what they are, but saw Bianca pouring tons of garlic powder in each and can smell waves of garlic coming from the kitchen:

a. (I don't know what Bianca is cooking, but given the smell ...) There's garlic in whatever dish Bianca is cooking now.

b. (Non so che cosa stia cucinando Bianca, It not know.1SG what thing be.SBJ.SG cooking Bianca ma visto il profumo...) but given the smell

* C'è dell'aglio in qualunque pietanza Bianca sta/stia cucinando ora. There's some-garlic in which-FC dish Bianca is/be.SBJ.SG cooking now

c. (Nu ştiu ce găteşte Bianca, dar după cum miroase...) Ro not know.1SG what cooks Bianca but after how smells

* Este usturoi în orice mâncare găteşte Bianca acum. is garlic in FC-what dish cooks Bianca now

d. (I don't know what Bianca is cooking, but given the smell ...)

* There's garlic in any dish Bianca is cooking now.

As observed by Dayal (1997, 2013a) for FC-any HRs and other FC items, the absence of a modal or a generic/habitual operator and the presence of indexicals like now or progressive aspect in the post-nominal modifier make the whole sentence episodic and degraded. We already saw above how a possibility modal helps improve the acceptability of FC-FRs and FC-any HRs. If the indexical material in (47) is removed and the sentences are turned into habitual statements about Bianca's cooking habits, the sentences with FC-FRs and any become acceptable as well, as shown in (48). The addition of a frequency adverb, e.g., usually, emphasizes the habitual interpretation, but its presence is not necessary.

\footnotetext{
${ }^{15}$ The distribution of any (and FC-FRs) with necessity modals is more complex than this example suggests. See Dayal (2013a,b) for an overview of FC any and FC-any HRs with different modals.
} 
(48) a. (Usually,) there's garlic in whatever dish Bianca cooks.

b. (Di solito,) c'è dell'aglio in qualunque pietanza Bianca It usually there's some-garlic in which-FC dish Bianca cucina/cucini. cooks/cook.SBJ.SG

c. (De obicei,) este usturoi în orice mâncare găteşte Bianca. Ro usually is garlic in FC-what dish cooks Bianca

d. (Usually,) there's garlic in any dish Bianca cooks.

In the next section, we will show that Dayal's observation has to be refined since the absence of an indexical and the presence of a modal are not necessary conditions for the licensing of FC-FRs and FC-any HRs.

Finally, Dayal (1997) noticed that imperatives and closely related deontic necessity modals license FC any. The same is true for FC-FRs. This pattern is illustrated in (49). The $\mathrm{x}$ ' examples illustrate the deontic option (modals in bold), while the $\mathrm{x}$ " examples illustrate the imperative option (imperative forms in bold).

CONTEXT: New regulations at the university since the terrorist attacks; from now on:

a'. The doorman must write down the name of whoever enters the building.

a". Write down the name of whoever enters the building!

b'. Il portiere deve scrivere il nome di chiunque acceda It the doorman must.3SG write the name of who-FC enter.SBJ.SG all'edificio. to-the-building

b".Scrivi il nome di chiunque acceda all'edificio! write.IMP.2SG the name of who-FC enter.SBJ.SG to-the-building

c'. Portarul trebuie să noteze numele oricui intră în clădire. $R o$ doorman-the must.3SG SUBJ write name-the FC-who.GEN enters in building

c". Notează numele oricui intră în clădire! Ro write.IMP.2SG name-the FC-who.GEN enters in building

d'. The doorman must write down the name of anyone who enters the building.

d". Write down the name of anyone who enters the building!

The examples listed above illustrate that FC-any HRs and FC-FRs have very similar distributional patterns. Their interpretive properties are also very much alike. Specifically, both FC-any HRs and FC-FRs can have universal-like interpretations, whereby any individual in the relevant quantificational domain has a certain property. This can be observed in contexts such as (48) and (49) above, which can easily be paraphrased with a universal quantifier. In addition, both can also have an existential interpretation, most clearly observed in certain imperative sentences. For example, by uttering (50), the speaker is giving permission to the addressee to pick a book (s)he likes and signals that (s)he is free to choose which one. ${ }^{16}$

\footnotetext{
${ }^{16}$ The Italian FC-FR in (50)b triggers an 'at least one' interpretation. By uttering it, the speaker is inviting the hearer to pick up one book or more. On the other hand, the Romanian (50)c and the English (50)d counterparts typically convey the meaning of "one and no more than one". This latter meaning can be rendered in Italian with the existential FC un qualunque + NP (cf. the detailed discussion in Chierchia 2013: Ch. 5). Notice that, unlike qualunque in FC-FRs, un qualunque does not behave like a wh-element, e.g., it does not move, and cannot introduce FC-FRs, but just headed relatives. This difference may be due to the fact that the wh-word qualunque introducing FC-FRs only selects for a singular NP as its complement, unlike
} 
(50) a. Pick whatever book you like!
b. Scegli
qualunque libro ti
piace/piaccia!
It choose.IMP.2SG which-FC book you.DAT likes/like.SBJ.SG
c. Alege orice carte îți place!
Ro pick.IMP.2SG FC-what book you.DAT like.3SG
d. Pick any book you like!

On the basis of the examples above, we conclude that (i) ignorance is not sufficient to warrant the acceptability of FC-FRs and (ii) FC-FRs and FC-any HRs have a very similar distribution and interpretation.

We now turn to the second modal inference that can arise in ever-FRs -indifference, illustrated in the example in (51)a, adapted from von Fintel (2000). The sentence signals indifference on the part of the agent/speaker, who grabbed a tool that was handy, without necessarily caring which tool it was. This is perfectly compatible with the agent knowing the identity of the tool, as confirmed by the fact that (51)a can be felicitously continued with an appositive relative clause naming the specific tool. However, the English sentence in (51)a cannot be rendered with a FC-FR in either Italian or Romanian, as shown by the unacceptability of the examples in (51)b-c. Once again, FC-any HRs patterns like FC-FRs (51)d. The examples in (52) provide a further illustration of this pattern:

(51) a. In that moment, I grabbed whatever tool was handy, which just happened to be a hammer.

b. * In quel momento, ho preso qualunque strumento fosse It in that moment, have.1SG grabbed which-FC tool be.SBJ.IMPF.SG

a portata di mano, nella fattispecie, un martello.

at reach of hand in-the case-under-discussion a hammer

c. * În acel moment, am luat orice unealtă îmi era Ro

in that moment, have.1SG grabbed FC-what tool me.DAT was

la îndemână, care s-a nimerit să fie un ciocan.

at hand REL REFL-has happened SBJ be a hammer

d. * In that moment, I picked up any tool that was handy, which just happened to be a hammer.

(52) a. Out of my mind, I punched whoever touched me first, which just happened to be my best friend.

b. * Fuori di testa, diedi un pugno a chiunque mi avesse toccato $I t$ out of head gave.1SG a punch to who-FC me have.SBJ.IMPF.SG touched per primo. Capitò che fosse il mio migliore amico. for first. happened that be.SBJ.IMPF.3SG the my best friend

c. * Luând-o razna, am lovit pe oricine m-a atins primul, Ro taking-it astray have.1SG hit ACC FC-who me-has touched first-the care s-a nimerit să fie prietenul meu cel mai bun. REL REFL-has happened SBJ be friend-the my the more good

d. * Out of my mind, I punched anybody who touched me first, which just happened to be my best friend.

English and Romanian. In Italian, qualunque libri 'any books' is completely unacceptable, while any books and orice cărți are fully well formed strings in English and Romanian, respectively, and can easily convey the "at least one" interpretation. 
Although the previous examples are ruled out, FC-FRs can sometimes signal indifference, as shown in the imperatives in (50) above and the sentences in (53). Crucially, though, an ability modal occurs in the matrix clause and the sentences receive a clear habitual/universal reading according to which, for every situation in which there is a place with a bed, the speaker can sleep there.

(53) a. I can sleep wherever there's a bed.

b. Posso dormire dovunque ci sia un letto. It can.1SG sleep where-FC there be.SBJ.SG a bed

c. Pot dormi oriunde este un pat. Ro can.1SG sleep FC-where is a bed

d. I can sleep anywhere there's a bed.

Taken together, the facts described above indicate that Italian and Romanian FC-FRs can convey both ignorance and indifference, just like ever-FRs, but the two constructions are subject to different semantic restrictions. Most importantly, the acceptability of the FC-FRs seems to depend on the presence of a modal(izing) operator in the matrix clause, a restriction that ever-FRs clearly lack. In other words, the morpho-syntactic similarity discussed in the previous section does not lead to identical semantic properties.

On the other hand, FC-FRs exhibit the very same semantic and pragmatic behavior as FC-any HRs, despite being morpho-syntactically different. FC-any HRs are not FRs syntactically, but nominals modified by headed relative clauses or PPs. Any itself is a determiner that is unrelated to wh-words and lacking morphological complexity (see Chierchia 2013, a.o.). Still, as shown in all the examples above, FC-any HRs are acceptable whenever FC-FRs are and are subject to the same kinds of semantic restrictions. In the next section, we will show that the parallelism between FC-FRs and FC-any HRs runs even deeper, by refining the generalization about their distribution and revealing further similarities between the two constructions.

\subsection{Further similarities with any: what counts as knowledge?}

Let us return to the distribution of any in purely episodic sentences, i.e., sentences referring to a single event, with the main predicate at the past perfective or non-futurate present progressive, without an overt modal nor any habitual, generic, futurate, or imperative form or marker. As is well-known, the unacceptability of any phrases in episodic sentences can be rescued by having a post-nominal modifier - a configuration called "subtrigging" (e.g., Legrand 1975, Dayal 1997):

(54) Yesterday, I talked to any student *(that stopped by).

However, Dayal (1997) observes that whenever the subtrigging phrase contains an indexical, the rescuing effect disappears: 
(55) CONTEXT: Luca can see that Bianca is cooking three dishes now. He does not know what they are, but saw Bianca pouring tons of garlic powder in each and can smell waves of garlic coming from the kitchen:

(I don't know what Bianca is cooking, but given the smell ...)

*There's garlic in any dish/dishes Bianca is cooking now.

It has been suggested that the ban on indexicals follows from the fact that FC items need some kind of variation concerning the individual satisfying a given property (e.g., Dayal 1997, 2013a; Giannakidou 2001; Jayez and Tovena 2005; Farkas 2006; Aloni 2007a,b; Menéndez-Benito 2010). Episodic sentences or subtrigging configurations with indexicals do not satisfy this requirement. For instance, the indexical in (55) would restrict the range of entities that are dishes Bianca is cooking to just those that Bianca is cooking right now in the actual world. We have seen that a similar constraint seems to be at play for FC-FRs, which also require a modal and seem incompatible with indexical material (cf. (47) above). The situation is more complicated though. Consider the following example:

(56) CONTEXT: Luca knows that Bianca always uses garlic for whatever she cooks. Luca is now upstairs and cannot see what Bianca is doing downstairs. Elena comes from downstairs and tells Luca that Bianca is cooking. Luca knows Elena hates garlic, so he warns her:

a. There's garlic in any dish/dishes Bianca is cooking now.

b. C'è dell'aglio in qualunque pietanza Bianca sta/stia cucinando ora. It there's some-garlic in which-FC dish Bianca is/be.SBJ.SG cooking now

c. Este usturoi în orice mâncare găteşte Bianca acum. Ro is garlic in FC-what dish cooks Bianca now

The sentences in (55) and (56) are identical and, crucially, both contain an indexical (in bold). The only difference is the context. In (55), Luca sees Bianca cooking three dishes, so he is visually "acquainted" with the dishes Bianca is cooking, though he does not know what they are nor can he identify the dishes Bianca is cooking (e.g., by naming or describing them in further details). In (56), instead, Luca has no visual contact nor any other form of "acquaintance" with the dishes Bianca is making. The two contexts differ in the presence vs. absence of what we may call an 'acquaintance relation'-a direct perceptual relationship_-between the speaker (or the relevant epistemic agent ${ }^{17}$ ) and the individuals (people, dishes, etc.) who constitute the extension of the property that is part of the meaning of the FC-any HR or the FC-FR. Ignorance about the name and further details characterizing the dishes is involved in both contexts, but acquaintance provides enough knowledge to make the FC construction in an episodic sentence infelicitous. In other words, while the full ignorance in context (56) allows for the three dishes Bianca is cooking right now to vary across worlds in all their dimensions and features, the acquaintance relation between the speaker and those three dishes in context (55) restricts the way those three dishes can vary across worlds enough to violate the FC-FR requirements.

The examples in (57) below reiterate this point: the sentences are all acceptable without the need to provide any specific context, despite the presence of three or more bolded indexicals in the FC-FRs and the FC-any HR.

\footnotetext{
${ }^{17}$ Cf. Dayal (2103a: ex. 50) and related discussion for a case in which the epistemic agent ('attitude holder' in her terminology) differs from the speaker.
} 
(57) a. The police arrested anybody who protested here in this building yesterday.

b. La polizia ha arrestato chiunque abbia protestato qui It the police has arrested who-FC have.SBJ.SG protested here

in questo edificio ieri.

in this building yesterday

c. Poliția a arestat pe oricine a protestat aici în clădirea Ro

police-the has arrested ACC FC-who has protested here in building-the

asta ieri.

this yesterday

However, if a specific context like the one in (58) is provided, the sentences in (57) become infelicitous. In the context in (58) Luca may not know the identity of the individuals the police arrested, but he saw them.

(58) CONTEXT: Yesterday, Luca saw four people he did not know protest in the building where he is now. He just heard that those people were all arrested. He says to Bianca...

To our knowledge, this kind of contrast has not been noticed for FC items like any. Most relevant for our present purpose is the fact that we once again find a parallel behavior between FC items and FC-FRs. The question is how to explain these contrasts. Clearly, they cannot be attributed to the indexicals, as these are present in some of the acceptable examples. We see that with minimal changes in the context, an example with a FC-any HR or with a FC-FR becomes felicitous. The challenge is to identify the determining contextual property, to which these constructions are sensitive. We do not have a full-fledged answer to this question, but we would like to offer some thoughts that could further our understanding of this issue.

These facts touch upon issues that have not received much attention in connection with FC elements (see however Jayez and Tovena 2005, 2006 and Chierchia 2013), namely those concerning (i) the kind of knowledge/ignorance at play and (ii) the source of evidence for a given claim (direct vs. indirect). However, these matters have been addressed in closely related areas like ever-FRs (e.g., Heller and Wolter 2011), epistemic modality and evidentiality (e.g., Matthewson, Davis and Rullman 2007), and epistemic indefinites (e.g., Alonso-Ovalle and Menéndez-Benito 2013; Aloni and Port 2015). These various lines of investigation show that it is complex and challenging to define what counts as the proper kind of knowledge or identification method, and moreover there is crosslinguistic variation in this respect. Taken together, these studies suggest that we are dealing with general, albeit poorly understood, semantic/pragmatic restrictions on expressions requiring variation in the quantificational domain (e.g., ever-FRs, FC-any nominals, FC-FRs, epistemic indefinites). Although these constructions vary along a series of other dimensions (quantificational force, distribution, modal inferences), the fact that they often exhibit similar knowledge and identification constraints suggests that it may be useful to consider a unified approach. For the purposes of the current investigation, we will assume that the descriptive constraint in (59) applies to FC-FRs in episodic sentences. 
(59) Constraint on AcQuainTAnce in EPISOdic SEnTEnCEs: speakers cannot use a FC-FR (or a FC-any HR) in an episodic sentence if they are "acquainted" with the set that is associated with the FC-FR in the world of evaluation, i.e., speakers have had a salient perceptual relationship with all the members of that set knowing that they and only they are members of that set.

The constraint in (59) requires that the speaker's (or some other relevant epistemic agent's) epistemic base allows for variation among the members of the relevant set. Being acquainted with the members of the set associated with a FC-FR in the world of evaluation is enough to prevent those members from varying across worlds, a variation that is at the core of free choice expressions. For instance, in our example in (55) above, Luca's visual acquaintance with the dishes Bianca is cooking suffices to set the extension of the property that the FC-FR is associated with - the set of dishes that Bianca is cooking now-across the worlds that are compatible with Luca's knowledge or epistemic state. In (56), instead, Luca has no acquaintance with the three dishes that Bianca is cooking right now. Therefore, his knowledge is compatible with Bianca currently cooking different sets of three dishes. This possibility of epistemic variation suffices to license the FC-FR in an episodic sentence. A similar story can be told for (57) and (58). Our Constraint on Acquaintance adds a novel observation about FC-FRs and FC items that enriches and broadens what scholars had previously noticed about their licensing conditions. At the end of Section 4.3 below, we suggest how this constraint can be integrated within a general theory of free choice.

The Constraint on Acquaintance is a necessary condition for the licensing of FC-FRs in episodic sentences. It is not a sufficient one. For instance, the examples of FC-FRs we discussed in (44)b-c above (repeated below as (60)a-b for convenience) are episodic and their context satisfies the Constraint on Acquaintance: the speaker has not seen and has not had any other form of acquaintance with the members of the set that is associated with the FC-FRs - the individuals who have access to the building. Still the sentences are completely unacceptable.

(60) CONTEXT: The speaker is aware that someone broke into the company last night but doesn't know who:
a. * È stato chiunque abbia
il codice di accesso all'edificio
It
is been who-FC have.SBJ.SG the code of access to-the-building
(sebbene non sappia chi sia).
though not know.SUBJ.SG who is.SBJ.SG
b. * A fost oricine avea codul de acces al clădirii ( deşi nu Ro
has been FC-who had code-the of access of building-the though not ştiu cine a fost).
know.1SG who it was.

The degraded status of (60)a-b is likely due to a clash between the semantic/pragmatic demands from the cleft structure and the semantic/pragmatic properties of the FC-FR. The cleft structure signals the speaker's intention to answer a question under discussion like 'Who did the breaking-in last night?', which asks for the identification of the individual(s) who broke in. The lack of a modal in the matrix signals the speaker's intention to provide an identification that is anchored just to the world of evaluation. On the other hand, the FC-FR and the ignorance context convey that the speaker is unable to associate just one set of individuals to the property of having the access code to the building in the world of evaluation. In fact, if a possibility modal is added to the matrix predicate, the sentences become fully acceptable, as we showed (45)b-c above. Also, if the FC-FRs are replaced 
with non-modalized nominals (e.g., plain indefinite), the resulting sentences are fully acceptable as well, as shown in (61).

(61) a. È stato qualcuno che ha il codice di accesso all'edificio. It is been somebody REL has.IND the code of access to-the-building

b. A fost cineva care are codul de acces al clădirii. Ro has been somebody REL has code-the of access of building-the 'It was somebody who has/had the access code to the building.'

The Constraint on Acquaintance has to be restricted to episodic sentences. Some of the modalized sentences licensing FC-FRs (and FC-any HRs) we discussed in the previous section are fully acceptable in a context in which the speaker is acquainted with the members of the set associated to the FC-FR, as shown in (62).

(62) CONTEXT: The speaker is sitting next to the hearer and they both have full sight of a keyboard that has a small yellow dot sticker on some of its buttons.
a. Puoi
premere qualunque pulsante abbia
il bollino giallo. It can.2SG push which-FC button have.SBJ.SG the dot-sticker yellow
b. Poți apăsa orice tastă care are o bulină galbenă.
Ro can.2SG push FC-what key REL has a dot-sticker yellow
c. You can push any button that has a yellow dot sticker on it.

Taking stock, we now have a clearer picture of the properties of FC-FRs in Italian and Romanian. Syntactically, they are headless non-interrogative wh-constructions like FRs, as attested, among others, by the exclusion of relative markers. English, Italian and Romanian do not display any notable difference concerning the syntactic structure of free relatives. Semantically, FC-FRs and ever-FRs show diverging properties. While ever-FRs are acceptable whenever the context is compatible with the ignorance or indifference implication they trigger, FC-FRs have a more restricted distribution. More precisely, we have shown that their semantic/pragmatic constraints parallel those exhibited by FC-any HRs: both constructions require a modal(izing) operator or, in episodic sentences, they ban contexts involving acquaintance with the members of the set associated with them.

\section{THE SEMANTICS OF FC-FRS AND THEIR WH-WORDS}

In this section, we first briefly review the literature on $\mathrm{FC}$ any and provide further evidence for the semantic similarity between FC-any HRs and FC-FRs (Section 4.1). Then we touch on previous studies of FC items other than FC-FRs in Romanian and Italian (Section 4.2). Third, we suggest a semantic analysis for FC-FRs building on the insights from the previous two sections (Section 4.3). Last, we focus on the semantic properties of FC wh-words and compare them with those of related items like FC-any and bare wh-words. Based on the previous sections, we conclude that FC-FRs should receive the same semantic analysis as FC-any HRs (Section 4.4).

\subsection{FC-FRs and FC-any HRs}

The semantics of FC-any HRs and of nominals introduced by FC any in general has attracted a lot of attention in the past decades. One of the core properties of FC-any and related FC items is their universal flavor: a sentence like You may pick any card is a statement about all the cards in the relevant context. The source of this universal force has been the subject of intense debate in the literature and a variety of accounts have been 
proposed (for a recent overview, see Dayal 2013a). These FC items have been analyzed as (non-quantificational) indefinites, whose quantificational force is due to (quantificational, modal or generic) operators in the context (e.g., Kadmon and Landman 1993; Horn 2000, 2005; Giannakidou 2001; Jayez and Tovena 2005, Menéndez-Benito 2005, 2010; Farkas 2006; Aloni 2007a,b). A different line of research treats them as quantifiers, either inherently universal (e.g., Reichenbach 1947; Dayal 1998, 2004; Sæbø 2001) or existentials (e.g., Chierchia 2006, 2013; Dayal 2013a,b), whose universal force comes about via meaning strengthening. A detailed comparison between these accounts is beyond the scope of this paper. For our purposes, it is important to note two things. First, any account that can successfully capture the distribution of FC-any nominals (including FC-any HRs) can in principle be extended to FC-FRs in Italian and Romanian. Second, the arguments showing that FC-any nominals are not merely indefinites carry over to FC-FRs. Most notably, just like FC-any nominals, FC-FRs do not have variable quantificational force (see Dayal 1998 for detailed discussion of this issue). Sentence (63)a shows that the bracketed complex indefinite can be quantified over by the quantificational adverb usually, ending up being equivalent to something like most people who protest. In contrast, (63)b only receives a frequency reading, according to which the police arrest protesters on most occasions, i.e., the FC-any HR does not inherit the quantificational force of the adverb:

(63) a. The police usually arrest [a person who protests (without authorization)].

b. The police usually arrest [any person who protests (without authorization)].

Turning to FC-FRs, we see that they exhibit a behavior similar to FC items: the quantificational adverb in the Italian and Romanian sentences in (64) can only be interpreted as a frequency adverb, quantifying over occasions. The sentences do not convey that the police arrest most of the protesters, but rather that on numerous occasions, the police arrest all the protesters:
a. La polizia spesso arresta [chiunque protesti (senza autorizzazione)]. It the police often arrests who-FC protest.SBJ.SG without authorization 'The police often arrest anybody who protests (without authorization).'
b. Adesea poliția arestează pe [oricine protestează (fără autorizație) $R o$ often police-the arrests ACC FC-who protests without authorization 'The police often arrest anybody who protests (without authorization).'

These facts further strengthen the similarity between FC constructions like FC-any HRs and the Italian and Romanian constructions under investigation that we have highlighted in the previous section.

\subsection{Previous work on FC in Romanian and Italian}

Although we are not aware of any previous semantic study on FC-FRs in Italian and Romanian, there have been insightful investigations of a related construction that we mentioned in Section 2: the FC Determiners orice/oricare $+\mathrm{NP}$ and qualunque $+\mathrm{NP}$ forming independent DPs without introducing a FC-FR. The fact that their free choice meaning is retained in the free relatives investigated in this paper is therefore not surprising.

For Romanian, Farkas (2002) is the first paper to mention orice/oricare + NP, which is shown to have the restricted distribution characteristic of FC-any (i.e., the need to be licensed by a modal or generic operator). Farkas $(2006,2013)$ further discusses the realm of FC determiners in Romanian and analyzes orice and oricare (the D-linked version of 
orice) as indefinite determiners that impose special restrictions on their evaluation. Specifically, they denote a special kind of set of alternatives (defined as individual-situation pairs), i.e., "maximal set of mutually exclusive undifferentiated alternatives", which can verify the expression in which the DP occurs (Farkas 2013: 221). The existence of a set of alternatives ensures that there are more possible values; the maximality of this set is responsible for the fact that each possible value can be considered. Furthermore, the fact that alternatives are undifferentiated means that the choice among them is free: whichever alternative is chosen, the orice-DP is verified. These requirements are shown to be met only when interacting with certain modal or generic operators, namely those operators that expand the situations which are part of the alternatives. This explains the restricted distribution of the Romanian FC determiners. The universal force is attributed to obligatory wide scope with respect to the licensing operator.

As for Italian, Aloni (2007b) is the first study to discuss the semantics of the FC qualunque + NP and analyze it as an existential. It also contains an explicit account of the semantics of free relatives and how they relate to qualunque $+\mathrm{NP}$ and free choice in general. Unlike plain existentials, qualunque $+\mathrm{NP}$ is argued to activate alternatives whose exhaustification produces the FC meaning. Chierchia (2013: Ch. 6) discusses the same construction as part of a larger crosslinguistic investigation and alternative-based approach to polarity-sensitivity and free choice phenomena. He endorses Aloni's view of qualunque + NP as an alternative-triggering existential, but raises crucial objections to Aloni's analysis that we fully agree on (cf. Chierchia 2013: Sec. 6.6.2). Chierchia argues that qualunque lexically activates scalar and domain alternatives. The exhaustification of these alternatives gives rise to two conflicting inferences: a FC inference, according to which all entities in the relevant domain are a possible value, and a scalar inference, according to which some but not all entities are a possible value. This conflict can only be resolved by certain modal operators, if slightly different modal bases are assumed for the FC and the scalar inferences. This assumption together with the requirement that the FC item take wide scope over modals derives the behavior of FC items.

Farkas' and Chierchia's analyses nicely capture the distribution of FC items in Romanian and Italian. They, together with Aloni (2007b), also address the issue of subtrigging - the rescuing of the $\mathrm{FC}$ element in otherwise illicit contexts by a post-nominal modifier (phrase or clause) (see (54)). Although they do not discuss FC-FRs directly, ${ }^{18}$ their insights strongly favor an analysis of FC-FRs as existentials with some extra semantic/pragmatic features triggering their FC properties.

\subsection{A proposal for the semantics of FC-FRs}

In this section, we propose a compositional semantic analysis for FC-FRs by building on the general view of FC expressions as having existential force and triggering alternatives obligatorily. We set aside important issues at the center of the debate like the kind of alternatives that are triggered and the nature and role of modality. Whatever consensus will be reached for FC constructions with any and alike, we expect it to apply to FC-FRs as well, given the identical semantic/pragmatic behavior we have documented in Section 3. We conclude by suggesting how this approach to FC-FRs can be integrated with our Constraint on Acquaintance in (59).

\footnotetext{
${ }^{18}$ To our knowledge, there are few papers investigating the relation between free choice items and free relative clauses with some form of free choice meaning. Horn (2000), Aloni (2007b), Dayal (2013b) and Condoravdi (2015) discuss the connection between ever-FRs and free choice items. Giannakidou and Cheng (2006) develop an account of Greek and Mandarin Chinese free choice items and their connection with ever-FRs. In this paper, we limit ourselves to data in Italian and Romanian, leaving a detailed crosslinguistic comparison for the future.
} 
The formula in (65) schematizes our assumption about the basic semantic contribution of a declarative sentence containing a FC-FR (and no other quantificational element).

(65) Basic meaning of a FC-FR:

$\exists \mathrm{x}_{1} \in \mathrm{D}\left[\mathrm{WH}\left(\mathrm{w}_{0}, \mathrm{x}_{1}\right) \wedge \mathrm{Mw}_{1} \in \mathrm{W}\left[\mathrm{a}, \mathrm{w}_{0}\right] \mathrm{P}\left(\mathrm{w}_{1}, \mathrm{x}_{1}\right) \wedge \mathrm{Q}\left(\mathrm{w}_{0}, \mathrm{x}_{1}\right)\right]$

This is an existentially quantified formula, reflecting our assumption that FC-FRs have the same basic meaning as existentials. The overt domain $D$ signals the obligatory triggering of domain alternatives, which we discuss below. The property $W H$ conveys the semantic restriction that comes with some wh-words (e.g., chiunque and oricine carry the semantic feature [+human]). The property $P$ conveys the semantic contribution of the IP of the FCFR (we call it a "property" rather than a "2-place relation" since only one of its arguments ranges over individuals, the other ranges over worlds). It is in the scope of a modal operator $\boldsymbol{M}$, which quantifies over worlds in the set $W$ and expresses the modal nature of FC-FRs. The worlds in $W$ depend on the epistemic agent $a$ at the world of evaluation $w_{0}$. The precise nature of $\boldsymbol{M}$ and the way it is licensed by the temporal and aspectual properties of the FC-FR (e.g., subjunctive in the Italian examples above) are important open issues that are not specific to FC-FRs, but, as mentioned earlier, extend to a fully compositional treatment of any FC expressions with clausal structure, including FC-any HRs (cf. Farkas 2002, 2006, 2013; Chierchia 2013; Dayal 2013a, among others). We believe that any valuable solution to those issues could be applied to our proposal. Finally, the property $Q$ conveys the semantic contribution of the IP of the matrix clause, which is often modalized (i.e., non-episodic) as well, although it does not have to (cf. Section 3.1 vs. Section 3.2 above).

Once the alternatives associated with the $\mathrm{FC}$ component are taken into account, the sentence with a FC-FR acquires the meaning of a universal, as schematized in (66).

(66) Enriched meaning of a FC-FR:

$\forall \mathrm{x}_{1} \in \mathrm{D}\left[\left[\mathrm{WH}\left(\mathrm{w}_{0}, \mathrm{x}_{1}\right) \wedge \mathrm{Mw}_{1} \in \mathrm{W}\left[\mathrm{a}, \mathrm{w}_{0}\right] \mathrm{P}\left(\mathrm{w}_{1}, \mathrm{x}_{1}\right)\right] \rightarrow \mathrm{Q}\left(\mathrm{w}_{0}, \mathrm{x}_{1}\right)\right]$

The details on the nature of the alternatives and the way they interact with the basic existential meaning to produce the meaning of a universal statement vary depending on the scholars and their proposals. In Section 4.2 above, we briefly sketched Farkas' and Chierchia's approaches. We will not endorse any specific proposal among those that have been suggested since, as far as we can tell, the data about FC-FRs do not provide evidence to favor one over the others. Still we will adopt some of the core ideas in Chierchia (2013) in order to discuss some examples in more detail and give a more precise idea of how an existential can end up meaning the same as a universal and how our Constraint on Acquaintance can play a role.

The following discussion will be centered on the Italian sentence in (67) for simplicity, but the very same could be said for the Romanian equivalent in (68) and all related examples with the same $\mathrm{FC}$-wh-words. 
(67) La polizia potrebbe arrestare [chiunque protesti]. It the police could arrest who-FC protest.SBJ.SG 'The police could arrest anybody who protests.'

(68) Poliția ar putea aresta pe [oricine protestează] Ro police-the CND can arrest ACC FC-who protests 'The police could arrest anybody who protests.'

The surface structure of (67) is given in (69) and shows the FC-FR in the object position of the matrix predicate with the $\mathrm{FC}$ wh-word moved to $\mathrm{CP}$ from its base-generated position, as the subject inside the IP of the FC-FR.

(69) a. [IP-1 La polizia potrebbe arrestare [CP chiunque $_{\mathrm{m}}\left[\mathrm{IP}-2_{2} \mathrm{t}_{\mathrm{m}}\right.$ protesti]]

b. $\mathrm{IP}_{1}$

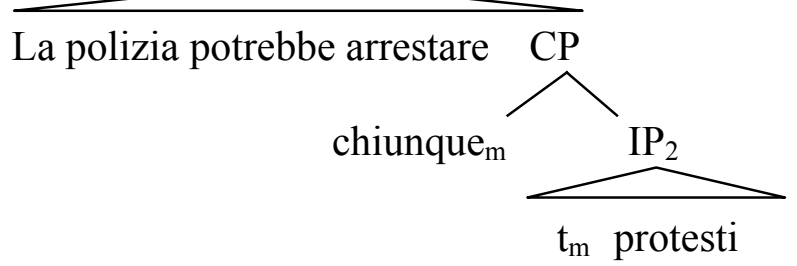

The Logical Form (LF) of (67) is given in (70). The FC-FR moves to the position of an IP adjunct to the matrix clause by $\mathrm{QR}$, just like any other quantificational argument.

(70) a. [IP -3 [CP chiunque ${ }_{m}\left[{ }_{\text {IP- }-2} t_{m}\right.$ protesti $\left.]\right]_{j}\left[I P-1\right.$ La polizia potrebbe arrestare $\left.\left.t_{j}\right]\right]$

b.

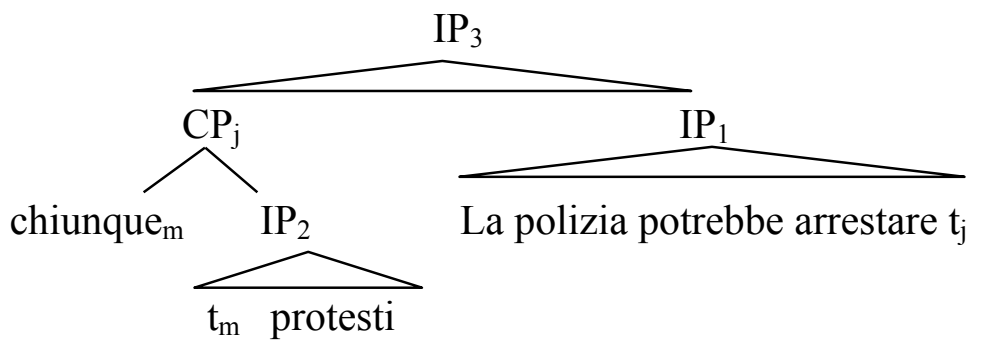

The logical translations of the main constituents in (70) are given in (71).

(71) a. chiunque $\mathrm{m}_{\mathrm{m}} \mid \lambda \mathrm{P} \lambda \mathrm{Q} \exists \mathrm{x}_{1} \in \mathrm{D}\left[\operatorname{hum}\left(\mathrm{x}_{1}\right) \wedge \mathrm{P}\left(\mathrm{x}_{1}\right) \wedge \mathrm{Q}\left(\mathrm{x}_{1}\right)\right]$

b. $\mathrm{IP}_{2} \mid \lambda \mathrm{x}_{1} \quad \mathrm{w}_{1} \in \mathrm{Ws}$ protest $\left(\mathrm{w}_{1}, \mathrm{x}_{1}\right)$

simplified as: $\lambda \mathrm{x}_{1} \quad \mathbf{1}, \mathrm{s}$ protest $\left(\mathrm{W}_{1}, \mathrm{x}_{1}\right)$

c. $\mathrm{IP}_{1} \mid \lambda \mathrm{x}_{1} \diamond \mathrm{w}_{2} \in \mathrm{Ws} \operatorname{arrest}\left(\mathrm{w}_{2}, \mathrm{p}, \mathrm{x}_{1}\right)$ simplified as: $\lambda \mathrm{x}_{1} \diamond_{2, \mathrm{~s}}$ arrest $\left(\mathrm{w}_{2}, \mathrm{p}, \mathrm{x}_{1}\right)$

d. $\quad \mathrm{CP}_{\mathrm{j}} \mid \lambda \mathrm{Q} \exists \mathrm{x}_{1} \in \mathrm{D}\left[\operatorname{hum}\left(\mathrm{x}_{1}\right) \wedge \mathbf{1 , s} \operatorname{protest}\left(\mathrm{w}_{1}, \mathrm{x}_{1}\right) \wedge \mathrm{Q}\left(\mathrm{x}_{1}\right)\right]$

e. $\operatorname{IP}_{3} \mid \exists \mathrm{x}_{1} \in \mathrm{D}\left[\operatorname{hum}\left(\mathrm{x}_{1}\right) \wedge \mathrm{1}, \mathrm{s} \operatorname{protest}\left(\mathrm{w}_{1}, \mathrm{x}_{1}\right) \wedge \diamond_{2, \mathrm{~s}} \operatorname{arrest}\left(\mathrm{w}_{2}, \mathrm{p}, \mathrm{x}_{1}\right)\right]$

(71)a provides the logical translation of the FC-wh-word: an existential generalized quantifier. It closely resembles the standard treatment of an existential DP, except for taking an IP rather than an NP as its restrictor and the presence of an overt domain $D$. (71)b provides the logical translation of the IP of the FC-FR. We assume that the modal in the FC-FR is a necessity modal ranging over the set $W_{S}$ of worlds $w_{l}$ that are compatible with 
the speaker S' knowledge, following Chierchia's (2013: Ch. 6) treatment of subtrigging (see Dayal 2013a for different assumptions on the strength of the modal). $w_{1} \in W s$ and its abbreviation $1, S$ can be read as "it is necessarily the case in view of what speaker $\mathrm{S}$ knows that." (71)c, the logical translation of the matrix IP is still a one-place modalized predicate like the translation of the FC-FR, but the epistemic modal has now existential strength and is triggered by the presence of the overt modal potrebbe 'could'. Finally, the logical translation in (71)e represents the basic meaning of (67) - the meaning (67) shares with a sentence in which the FC item is replaced by a plain existential.

The next step of the semantic derivation introduces the meaning component that differentiates FC items from plain existentials: obligatory alternatives. In order to calculate actual alternatives, we need to choose a specific domain D. Let us assume that D contains only two members: $b$ and $c$. Such a small domain may not be the most natural assumption for a sentence with a FC item, but it keeps our calculation simpler and easier to follow. The logical translation in (71)e can then be rewritten as (72) by overtly stating $D=\{b, c\}$. Intuitively, (72) asserts that between the individuals $b$ and $c$, at least one of them is a human being that, according to the speaker's knowledge, protests for sure and could be arrested by the police. (72) is equivalent to (73) and (74), two ways of exemplifying the well-known connection between existential quantification and disjunction. (73) states that there is at least one member in the domain $\mathrm{D}_{1}=\{\mathrm{b}\}$ (a subset of the domain $\mathrm{D}$ ), that participates in the given relations and/or that there is at least one member in the domain $\mathrm{D}_{2}=\{\mathrm{c}\}$ (another subset of the domain D) that participates in the given relations. In turn, (73) is equivalent to stating, as in (74), that $b$ participates in those relations and/or $c$ does.

$$
\begin{aligned}
& \left.\exists x_{1} \in D=\{b, c\}\left[h u m\left(x_{1}\right) \wedge 1, s \operatorname{protest}\left(w_{1}, x_{1}\right) \wedge \diamond_{2, s} \operatorname{arrest}\left(w_{2}, p, x_{1}\right)\right]\right] \\
& \text { (73) } \exists \mathrm{x}_{1} \in \mathrm{D}_{1}=\{\mathrm{b}\}\left[\operatorname{hum}\left(\mathrm{x}_{1}\right) \wedge 1, \mathrm{~s} \operatorname{protest}\left(\mathrm{w}_{1}, \mathrm{x}_{1}\right) \wedge \diamond_{2, \mathrm{~s}}\left(\mathrm{w}_{2}, \mathrm{p}, \mathrm{x}_{1}\right)\right] \vee \\
& \exists \mathrm{x}_{1} \in \mathrm{D}_{2}=\{\mathrm{c}\}\left[\operatorname{hum}\left(\mathrm{x}_{1}\right) \wedge \mathbf{1 , \mathrm { s }} \operatorname{protest}\left(\mathrm{w}_{1}, \mathrm{x}_{1}\right) \wedge \diamond_{2, \mathrm{~S}} \operatorname{arrest}\left(\mathrm{w}_{2}, \mathrm{p}, \mathrm{x}_{1}\right)\right]
\end{aligned}
$$

$$
\begin{aligned}
& {\left[\operatorname{hum}(b) \wedge 1, \mathrm{p} \operatorname{protest}\left(\mathrm{w}_{1}, \mathrm{~b}\right) \wedge \diamond_{2, \mathrm{~S}} \operatorname{arrest}\left[\left(\mathrm{w}_{2}, \mathrm{p}, \mathrm{b}\right)\right] \vee\right.} \\
& {\left[\operatorname{hum}(\mathrm{c}) \wedge 1, \mathrm{p} \operatorname{protest}\left(\mathrm{w}_{1}, \mathrm{c}\right) \wedge \diamond_{2, \mathrm{~S}} \operatorname{arrest}\left(\mathrm{w}_{2}, \mathrm{p}, \mathrm{c}\right)\right]}
\end{aligned}
$$

Each disjunct in (73) or (74) exemplifies what Chierchia calls a "subdomain alternative" of (72). Henceforth, we will use the abbreviations in (75). Notice that the abbreviation for each formula is the capitalized form of the same letter that is used for the individual constant that is assigned as the value of the individual variable in the very same formula.

$$
\begin{aligned}
& \mathrm{B}=\left[\operatorname{hum}(\mathrm{b}) \wedge \quad 1, \mathrm{p} \operatorname{protest}\left(\mathrm{w}_{1}, \mathrm{~b}\right) \wedge \diamond_{2, \mathrm{~S}} \operatorname{arrest}\left(\mathrm{w}_{2}, \mathrm{p}, \mathrm{b}\right)\right] \\
& \mathrm{C}=\left[\operatorname{hum}(\mathrm{c}) \wedge \quad \mathbf{1 , \mathrm { S }} \operatorname{protest}\left(\mathrm{w}_{1}, \mathrm{c}\right) \wedge \diamond_{2, \mathrm{~S}} \operatorname{arrest}\left(\mathrm{w}_{2}, \mathrm{p}, \mathrm{c}\right)\right]
\end{aligned}
$$

The alternatives $\mathrm{B}$ and $\mathrm{C}$ are obligatorily activated by free choice expressions and capture the intuition that free choice items are associated with variation or different choices. Each alternative conveys a different state of affairs, each of which is compatible with (74). Next, the alternatives in (75) are combined with the basic meaning in (74) by a two-step procedure (cf. Chierchia 2013 and references therein for motivations). First, alternatives have to undergo exhaustification $(E X H)$, i.e., each of them is conjoined with the negation of all the other (non-entailed) alternatives, as in (76). 
(76)

$$
\begin{aligned}
& \operatorname{EXH}(b)=\mathrm{B} \wedge \sim \mathrm{C} \\
& \operatorname{EXH}(\mathrm{c})=\mathrm{C} \wedge \sim \mathrm{B}
\end{aligned}
$$

$E X H$ can be thought as a silent only-an operator that applies to the propositional content $p$ of a sentence and to all its alternatives and asserts the truth of $p$ together with the falsity of all the alternatives that are not entailed by $p$. Therefore, $E X H(B)$ says that $b$ protests for sure and could be arrested, while it is not true that $c$ protests for sure and could be arrested. Since there are no other individuals in $\mathrm{D}$ besides $b$ and $c$, this is equivalent to saying that $b$ is the only one who protests for sure and could be arrested. Similarly, $E X H(C)$ says that $c$ is the only one who protests for sure and could be arrested.

The second step conjoins the negated exhaustified alternatives in (76) with the basic meaning $\mathrm{B} \vee \mathrm{C}$ in $(74) /(75)$, as shown in (77). This is just a new application of the same exhaustification operator $E X H$, which now applies to the basic meaning in $(74) /(75)$ rather than its alternatives. In other words, we are applying $E X H$ recursively. The final result of the calculation is the conjunction of the two alternatives $\mathrm{B} \wedge \mathrm{C}$, which is equivalent to the universal statement in (78).

$$
\begin{aligned}
& \mathrm{EXH}([\mathrm{B} \vee \mathrm{C}])= \\
& {[\mathrm{B} \vee \mathrm{C}] \wedge \sim \mathrm{EXH}(\mathrm{B}) \wedge \sim \mathrm{EXH}(\mathrm{C})=} \\
& {[\mathrm{B} \vee \mathrm{C}] \wedge \sim[\mathrm{B} \wedge \sim \mathrm{C}] \wedge \sim[\mathrm{C} \wedge \sim \mathrm{B}]=} \\
& {[\mathrm{B} \vee \mathrm{C}] \wedge[\mathrm{B} \rightarrow \mathrm{C}] \wedge[\mathrm{C} \rightarrow \mathrm{B}]=} \\
& \mathrm{B} \wedge \mathrm{C}
\end{aligned}
$$

$$
\forall \mathrm{x}_{1} \in \mathrm{D}=\{\mathrm{b}, \mathrm{c}\}\left[\left[\operatorname{hum}\left(\mathrm{x}_{1}\right) \wedge \quad \mathbf{1 , \mathrm { s }} \operatorname{protest}\left(\mathrm{w}_{1}, \mathrm{x}_{1}\right)\right] \rightarrow \diamond_{2, \mathrm{~s}} \operatorname{arrest}\left(\mathrm{w}_{2}, \mathrm{p}, \mathrm{x}_{1}\right)\right]
$$

This quick sketch gives an idea of how a universal interpretation of FC-FRs can be derived from a plain existential meaning via an alternative-based semantic enrichment. Something more is needed, though, since this approach overgenerates and wrongly predicts FC items to be acceptable (and receive a universal interpretation) in any sentences, including the unacceptable cases we discussed in Section 3. We briefly mentioned Chierchia's (2013: Ch. 6) solution to this problem at the end of Section 4.2 and we refer the interested reader to Chierchia's work (or Dayal 2013a for another alternative-based solution).

We would like to discuss at least one problematic case, though, which has not been noticed so far: the variable acceptability of FC-FRs in purely episodic sentences we described in Section 3.2. We conclude this section by showing how those facts and the Constraint on Acquaintance we introduced to describe them can be derived on the alternative-based theory presented above. The sentence in (79) is a simplified version (without indexical adjuncts) of our earlier example in (57)b. It is an episodic sentence with no overt or covert modal in the matrix clause. As discussed in Section 3.2, its acceptability crucially depends on whether the context satisfies the Constraint on Acquaintance in (59), i.e., whether the speaker is acquainted with the individuals that the police arrested. Why should this be the case?

(79) La polizia ha arrestato chiunque abbia protestato. It the police has arrested who-FC have.SBJ.SG protested 'The police arrested anybody who protested.'

The syntactic structure of (79) is the same as (69) and (70) above, while the logical translation of its basic semantic contribution in (80) is slightly but crucially different from (71)e: the matrix clause contains no modal (for the sake of simplicity, we ignore the fact 
that the temporal morpho-syntactic marking in both the matrix clause and FC-FRs translate into two Past operators).

(80) Basic meaning of (79):

$$
\exists \mathrm{x}_{1} \in \mathrm{D}\left[\operatorname{hum}\left(\mathrm{x}_{1}\right) \wedge \mathbf{1 , \mathrm { s }} \operatorname{protest}\left(\mathrm{w}_{1}, \mathrm{x}_{1}\right) \wedge \operatorname{arrest}\left(\mathrm{w}_{0}, \mathrm{p}, \mathrm{x}_{1}\right)\right]
$$

Let us once again assume a context in which, according to the speaker's knowledge, $b$ or $c$ are the only possible individuals the police arrested who could have protested, although the speaker does not know which. Since $b$ or $c$ are the only individuals who could have protested in this context and the speaker has not seen either of them protest, then the speaker is not acquainted with the individual(s) who protested and (79) is predicted to be acceptable with the basic meaning in (81) and the enriched meaning in (82), resulting from essentially the same calculation as the one we just went through for (67).

(81) Basic meaning of (79) for $D=\{b, c\}$ :

$$
\exists \mathrm{x}_{1} \in \mathrm{D}=\{\mathrm{b}, \mathrm{c}\}\left[\operatorname{hum}\left(\mathrm{x}_{1}\right) \wedge \mathbf{1 , s} \operatorname{protest}\left(\mathrm{w}_{1}, \mathrm{x}_{1}\right) \wedge \operatorname{arrest}\left(\mathrm{w}_{0}, \mathrm{p}, \mathrm{x}_{1}\right)\right]
$$

(82) Enriched meaning of (79) for $D=\{b, c\}$ :

$$
\left.\forall \mathrm{x}_{1} \in \mathrm{D}=\{\mathrm{b}, \mathrm{c}\}\left[\left[\operatorname{hum}\left(\mathrm{x}_{1}\right) \wedge \mathbf{1 , \mathrm { s }} \operatorname{protest}\left(\mathrm{w}_{1}, \mathrm{x}_{1}\right)\right] \rightarrow \operatorname{arrest}\left(\mathrm{w}_{0}, \mathrm{p}, \mathrm{x}_{1}\right)\right]\right]
$$

Let us now assume that $b$ is the only individual that protested and the speaker is acquainted with $b$, e.g., by seeing $b$ protest alone. The speaker does not know $b$ 's name or anything specific about $b$, but does know that it was $b$ who protested and $b$ was the only one. In this context, the domain $D$ is a singleton: $\mathrm{D}=\{\mathrm{b}\}$. The speaker's epistemic state is such that there is no choice or possible variation as far as the individual who protested and was arrested. If we go through the same calculation we went through for the previous example, the basic meaning of (79) is the one in (83), the only domain alternative is the one in (84), i.e., the assertion. The exhaustification of this single alternative can only return the very same alternative, as shown in (85). Therefore, the exhaustification of the basic meaning in (81) is in a sense vacuous, i.e., it simply returns the assertion. In the case of our singleton domain $\mathrm{D}$, this amounts to any of the formulations in (86).

(83) Basic meaning of (79) for $D=\{b\}$ :

$\exists \mathrm{x}_{1} \in \mathrm{D}=\{\mathrm{b}\}\left[\operatorname{hum}\left(\mathrm{x}_{1}\right) \wedge \mathbf{1 , s} \operatorname{protest}\left(\mathrm{w}_{1}, \mathrm{x}_{1}\right) \wedge \operatorname{arrest}\left(\mathrm{w}_{0}, \mathrm{p}, \mathrm{x}_{1}\right)\right]=$

$\operatorname{hum}(\mathrm{b}) \wedge 1, \mathrm{p} \operatorname{protest}\left(\mathrm{w}_{1}, \mathrm{~b}\right) \wedge \operatorname{arrest}\left(\mathrm{w}_{0}, \mathrm{p}, \mathrm{b}\right)$

$$
\mathrm{B}=\left[\operatorname{hum}(\mathrm{b}) \wedge \quad \mathbf{1 , \mathbf { s }} \operatorname{protest}\left(\mathrm{w}_{1}, \mathrm{~b}\right) \wedge \operatorname{arrest}\left(\mathrm{w}_{0}, \mathrm{p}, \mathrm{b}\right)\right]
$$

(85) $\operatorname{EXH}(\mathrm{B})=\mathrm{B}$

(86) Enriched meaning of (79) for $D=\{b\}$ :

$\mathrm{B}=$

$\operatorname{hum}(\mathrm{b}) \wedge 1, \mathrm{~s} \operatorname{protest}\left(\mathrm{w}_{1}, \mathrm{~b}\right) \wedge \operatorname{arrest}\left(\mathrm{w}_{0}, \mathrm{p}, \mathrm{b}\right)=$

$\exists \mathrm{x}_{1} \in \mathrm{D}=\{\mathrm{b}\}\left[\operatorname{hum}\left(\mathrm{x}_{1}\right) \wedge \mathbf{1 , \mathrm { s }} \operatorname{protest}\left(\mathrm{w}_{1}, \mathrm{x}_{1}\right) \wedge \operatorname{arrest}\left(\mathrm{w}_{0}, \mathrm{p}, \mathrm{x}_{1}\right)\right]=$

$\left.\forall \mathrm{x}_{1} \in \mathrm{D}=\{\mathrm{b}\}\left[\left[\operatorname{hum}\left(\mathrm{x}_{1}\right) \wedge \mathbf{1 , \mathrm { s }} \operatorname{protest}\left(\mathrm{w}_{1}, \mathrm{x}_{1}\right)\right] \rightarrow \operatorname{arrest}\left(\mathrm{w}_{0}, \mathrm{p}, \mathrm{x}_{1}\right)\right]\right]$

The resulting meaning is at odds with at least two independently motivated constraints. First, it violates a general ban on quantification over singleton sets (Chierchia 2013: p. 202, fn. 10). The sentences in (87) in which a headed relative is introduced by a plain existential 
or a universal quantifier sounds awkward in a situation in which it is contextually known that only one person protested or there is only one current President of the United States.

(87) a. The police arrested a/every person who protested.

b. The police arrested a/every current President of the United States.

Second, it violates a ban against vacuous enrichment, since the basic meaning in (83) and the enriched meaning in (86) are the same. Chierchia (2013: Sec. 5.4.2, Sec. 6.5.2) has labelled this the "Proper Strengthening Parameter" and has argued that it is needed to account for the fact that some FC items do not behave like Negative Polarity Items and dislike negative contexts. This is true for FC-FRs as well. The examples in (88) are awkward out of the blue as a reply to a broad question that does not presuppose any shared specific knowledge. They become acceptable only if somebody had previously uttered the positive counterparts of (88)a-b and the speaker wants to correct that statement (a use of negation that is often called "metalinguistic"; cf. Horn 1989: Ch. 6)

(88) CONTEXT: Somebody asked 'What happened?' and the speaker answers:

a. *La polizia non ha arrestato chiunque abbia protestato. It the police not has arrested who-FC have.SBJ.SG protested

'The police did not arrest anybody who protested.'

b. *Politia nu a arestat pe oricine a protestat Ro police-the not has arrested ACC FC-who has protested 'The police did not arrest anybody who protested.'

Notice that the same violations would occur had the speaker seen both $b$ and $c$ protest. The domain D would still be a singleton set containing just the plural individual $b+c$, since the speaker would know that $b$ and $c$ together were the ones protesting. The more general point is that, if the speaker is acquainted with the individuals satisfying the property associated to the FC-FR, then the speaker's knowledge would only be compatible with worlds in which those individuals and only they have that property. So there would not be any variation, or uncertainty, or possibility of choice in the set D. Differently put, the Constraint on Acquaintance follows from a more general ban on vacuous exhaustification. On the other hand, if the speaker is not acquainted with the members of $\mathrm{D}$, exhaustification can go through and we obtain a consistent enriched meaning, i.e., the universal interpretation of the FC element.

\subsection{FC wh-words and their kin}

In the previous section, we provided a compositional semantics for FC-FRs in Italian and Romanian. In this section, we highlight the main morpho-syntactic and semantic properties of their FC wh-words and compare them with those of related lexical items like FC-any in English, bare wh-words in Italian and Romanian, and FC wh-words occurring without FCFRs. Our discussion will focus on the FC wh-words chiunque and oricine 'who+FC' for the sake of simplicity and brevity, but we conclude with some more general remarks.

The main properties of chiunque and oricine are summarized in (89). They are morphologically complex, as discussed earlier (Section 2.2). Syntactically, they undergo wh-movement to the left edge of the FC-FR they are part of and license a DP gap in their base-generated position, as assumed in the syntactic and semantic analyses above (Sections 2.1 and 4.3, respectively). Semantically, chiunque and oricine behave like a standard existential determiner (e.g., some) in taking two set-denoting expressions as their two 
arguments. Unlike a standard existential determiner, chiunque and oricine take two IPs as their arguments, rather than an NP and then an IP. They first combine with the IP containing the remainder of their FC-FR after they underwent wh-movement; then the whole FC-FR they are now heading combines with the remainder of the matrix clause after it has moved by quantifier raising, as detailed in Section 4.3. Therefore, the syntactic property we labelled "selection" in (89)b.iii should be understood as a mnemonic for this semantically driven complex combinatory process. Chiunque and oricine also introduce a semantic restriction to just humans and activate the kind of alternatives characterizing FC items.

\section{(89) chiunque and oricine in FC-FRs:}

a. Morphological properties:

i. morphologically complex

ii. wh-word (chi/cine 'who') + FC affix (-unque/ori-)

b. Syntactic properties:

i. licensing a DP gap

ii. undergoing wh-movement

iii. selection: _ $\mathrm{IP}_{1} \mathrm{IP}_{2}$

c. Semantic properties:

i. logical translation: $\lambda \mathrm{P} \lambda \mathrm{Q} \exists \mathrm{x}_{1} \in \mathrm{D}\left[\operatorname{hum}\left(\mathrm{x}_{1}\right) \wedge \mathrm{P}\left(\mathrm{x}_{1}\right) \wedge \mathrm{Q}\left(\mathrm{x}_{1}\right)\right]$

ii. semantic type: $<$ et, $<$ et, $t>>$

iii. introducing a [+human] semantic restriction

iv. activating alternatives

Let us now compare chiunque and oricine with FC any. The main properties of FC any are summarized in (90). Chiunque and oricine and FC any share all semantic properties but the [+human] restriction. On the other hand, they differ morpho-syntactically: FC any is morphologically simple, behaves like a D head rather than a full DP, does not undergo wh-movement, and selects for an NP argument first, rather than an IP.

(90) FC any:

a. Morphological properties:

i. morphologically simple

b. Syntactic properties:

i. syntactic category: D

ii. selection: _ NP IP

c. Semantic properties:

i. logical translation: $\lambda \mathrm{P} \lambda \mathrm{Q} \exists \mathrm{x}_{1} \in \mathrm{D}\left[\mathrm{P}\left(\mathrm{x}_{1}\right) \wedge \mathrm{Q}\left(\mathrm{x}_{1}\right)\right]$

ii. semantic type: $<$ et, $<$ et,,$>>$

iii. activating alternatives

Next, we turn to the comparison between chiunque and oricine and their wh-roots (and independent wh-words) chi and cine 'who'. We summarized their main properties in (91). All four wh-words share the syntactic properties of undergoing wh-movement and licensing a DP gap and the semantic property of introducing a [+human] restriction. On the other hand, chi and cine are morphologically simple, only take one argument — an IP —and there is no evidence they behave like quantifiers. As for their semantic properties, it has been argued that wh-words in plain free relatives lack quantificational force and behave like set restrictors (91)c.i-ii and the same semantic treatment can be extended to whinterrogatives as well (Caponigro 2003, 2004). 


\section{(91) chi and cine:}

a. Morphological properties:

i. morphologically simple

b. Syntactic properties:

i. licensing a DP gap

ii. undergoing wh-movement

iii. selection: IP

c. Semantic properties:

i. logical translation: $\lambda \mathrm{P} \lambda \mathrm{x}_{1}\left[\operatorname{hum}\left(\mathrm{x}_{1}\right) \wedge \mathrm{P}\left(\mathrm{x}_{1}\right)\right]$

ii. semantic type: $<$ et,et $>$

iii. introducing a [+human] semantic restriction

The comparison of chiunque and oricine with chi and cine highlights the fact that the morphologically simpler forms are also semantically and syntactically simpler and suggests that the syntactic and semantic properties of the FC affixes are responsible for turning wh-words from non-quantificational, mono-argumental, alternative-inert items into full-fledged FC creatures. (92) spells out these conclusions.

\section{(92) Semantic properties of FC affixes -unque/ori- :}

i. logical translation: $\lambda \mathrm{WH}_{<\mathrm{et}, \mathrm{et}>} \lambda \mathrm{P} \lambda \mathrm{Q} \exists \mathrm{x}_{1} \in \mathrm{D}\left[\mathrm{WH}\left(\mathrm{x}_{1}\right)(\mathrm{P}) \wedge \mathrm{Q}\left(\mathrm{x}_{1}\right)\right]$

ii. semantic type: $<<$ et, et $>,<<$ et, $<$ et, $\mathrm{t}>>>>$

iii. activating alternatives

Technical details aside, (92) shows that there is a precise and compositional way to turn a wh-word into a FC item. Such a process has to happen in the morphology, though, rather than the syntax, because the FC marker is an affix in Italian and Romanian and, more crucially, the change from bare wh-words to FC-wh-words exhibits idiosyncratic restrictions within a given language and across languages (cf. Section 2.2).

The differences between FC wh-words and bare wh-words we highlighted above have repercussions on the semantic behavior of the whole wh-constructions they introduce. FC wh-words are mainly responsible for making FC-FRs behave like existentially quantified expressions with a FC dimension added to their meaning via alternative computation. On the other hand, bare wh-words' behavior as set restrictors is responsible for the basic meaning of a plain FR: a set. ${ }^{19}$

At the end of Section 2.2, we showed that chiunque, oricine, and all other FC wh-words can be used independently without FC-FRs and that this was a later historical development from their use in FC-FRs. Our analysis can capture this fact by assuming that chiunque and oricine are listed in the lexicons of both languages in two slightly different variants: the one introducing FC-FRs that we just discussed in (89) and another occurring without a FC-FR. The latter exhibits the same properties as the former, except for the following: syntactically, it does not undergo wh-movement and therefore does not license any gap; semantically, it behaves like an existential generalized quantifier looking for one set-denoting IP argument, rather than an existential determiner looking for two set-denoting IP arguments, as shown in (93). The dropped IP argument is the semantic counterpart of the syntactic fact that chiunque and oricine occur as independent DPs, without introducing FC-FRs.

\footnotetext{
${ }^{19}$ For ways to derive the final meaning of FRs as definite descriptions from a set denotation via type-shifting, see Jacobson (1995), Caponigro (2003, 2004), and Aloni (2007b).
} 


$$
\begin{array}{r}
\text { chiunque/oricine (without a FC-FR) } \mid \lambda \mathrm{Q} \exists \mathrm{x}_{1} \in \mathrm{D}\left[\mathrm{hum}\left(\mathrm{x}_{1}\right) \wedge \mathrm{Q}\left(\mathrm{x}_{1}\right)\right](\text { cf. }(89) \mathrm{c} . \mathrm{i}) \\
\text { Semantic type: }<\text { et, } \mathrm{t}>
\end{array}
$$

Notice that the "argument-demoting" process above is independently attested in non-wh FC items like any or non-FC items like every, some, or no. The forms anybody, everybody, somebody, and nobody can be analyzed as resulting from a morphological process in which a bi-argumental quantificational head $\mathrm{D}$ is combined with the morpheme body (which carries the semantic feature [+human]) to produce a full DP behaving like a generalized quantifier and looking for just one argument, as shown in (94) for any/anybody.

$$
\begin{aligned}
& \text { a. any } \mid \lambda \mathrm{P} \lambda \mathrm{Q} \exists \mathrm{x}_{1} \in \mathrm{D}\left[\mathrm{P}\left(\mathrm{x}_{1}\right) \wedge \mathrm{Q}\left(\mathrm{x}_{1}\right)\right] \\
& \text { b. anybody } \mid \lambda \mathrm{Q} \exists \mathrm{x}_{1} \in \mathrm{D}\left[\operatorname{hum}\left(\mathrm{x}_{1}\right) \wedge \mathrm{Q}\left(\mathrm{x}_{1}\right)\right]
\end{aligned}
$$

Another reason why these similarities are interesting is because they show that once the FC-morpheme is added to a wh-word, the resulting item can behave more like other, better known quantificational DPs. If a FC-wh-word starts as a complex function like in (89)c.i and loses one argument, it turns into a simpler and well-known function-a generalized quantifier, as in (93). Generalized quantifiers constitute the default interpretation for (quantificational) DPs, at least since Montague's seminal work (Montague 1973). Therefore, this minimal semantic change in the lexical entries for chiunque and oricine produces a well-attested type of semantic object, but it also enriches the expressive power of Italian and Romanian with a new generalized quantifier with a FC meaning component. In other words, the loss of an argument for a FC wh-word, far from being surprising, is almost expected. On the other hand, if bare wh-words, which start as set restrictors $\left(\lambda \mathrm{P} \lambda \mathrm{x}_{1}\left[\mathrm{WH}\left(\mathrm{x}_{1}\right) \wedge \mathrm{P}\left(\mathrm{x}_{1}\right)\right]\right)$, lost an argument, they would turn into set-denoting expressions $\left(\lambda \mathrm{x}_{1} \mathrm{WH}\left(\mathrm{x}_{1}\right)\right)$. A set-denoting expression is not the default meaning for a DP in Italian or Romanian. Either a rule changing lexical meaning (e.g., a type-shifting rule) or a richer set of combinatory rules (e.g., pointwise function application à la Hamblin) would be required to be independently available in those languages and to extend its effects to bare whwords. ${ }^{20}$ This extra semantic work would not produce any new semantic object, though. Depending on the specific implementation, $\lambda \mathrm{x}_{1} \mathrm{WH}\left(\mathrm{x}_{1}\right)$ would end up producing the same meanings as what is already straightforwardly conveyed by definite DPs or existentially quantified DPs in the two languages. Lots of semantic work for no gain in expressive power does not look like a strong incentive for a lexical shift.

The remarks and conclusions above straightforwardly extend to other phrasal FC wh-words like orice 'FC-what' in Romanian, the only difference being the lack of the [+human] semantic restriction. Phrasal wh-words like dovunque 'where-FC' in Italian and oriunde 'FC-where', oricând 'FC-when', and oricum 'FC-how' in Romanian preserve the same bi-argumental structure, although their domain of quantification may require some further discussion, depending on whether places, time units/intervals, and manners are treated as individuals or more complex semantic objects (cf. Caponigro 2003, 2004; Caponigro and Pearl 2008, 2009).

FC wh-words that combine with other elements to form a full wh-phrase take one more argument. FC wh-determiners like qualunque 'what/which-FC' in Italian and orice 'FC-what' and oricare 'FC-which' in Romanian combine with an NP first to form a full

\footnotetext{
${ }^{20}$ It is well-known that there are languages in which bare wh-words can easily occur without a wh-clause (e.g., Mandarin, Japanese, Korean, among many others). Interestingly, these are all wh-in-situ languages lacking FRs. There seems to be a very strong tendency for FRs introduced by wh-words to be allowed only in languages with wh-movement. So far, the only possible exception we are familiar with is Tsez (Polinsky 2015), though more work needs to be done on those constructions to fully access their productivity and nature.
} 
DP, then with the remainder of the FC-FR, and finally with their matrix clause (95). In other words, they behave like quantificational determiners with an extra argument. Still, their domain of quantification is the same as for phrasal wh-words-individuals.

(95) qualunque/orice/oricare + NP in FC-FRs:

a. Morphological properties:

i. morphologically complex

ii. wh-word + FC affix

b. Syntactic properties:

i. distribution as a D

ii. contributing to license a DP gap

iii. undergoing wh-movement

iv. selection: _ NP IP $\mathrm{IP}_{2}$

c. Semantic properties:

i. logical translation: $\lambda \mathrm{Z} \lambda \mathrm{P} \lambda \mathrm{Q} \exists \mathrm{x}_{1} \in \mathrm{D}\left[\mathrm{Z}\left(\mathrm{x}_{1}\right) \wedge \mathrm{P}\left(\mathrm{x}_{1}\right) \wedge \mathrm{Q}\left(\mathrm{x}_{1}\right)\right]$

ii. semantic type: $<\mathrm{et},<\mathrm{et},<\mathrm{et}, \mathrm{t}>>>$

iii. activating alternatives

Like FC wh-DPs chiunque and oricine, $\mathrm{FC}$ wh-Determiners qualunque, orice, and oricare can occur in independent DPs that do not undergo wh-movement nor introduce FC-FRs (cf. end of Section 2.2). As we argued for FC phrasal wh-words, qualunque, orice, and oricare must also select for one less argument when used without a FC-FR, as can be seen by comparing (96) below with (95)c.i above.

$$
\text { qualunque/orice/oricare (without a FC-FR) } \mid \lambda \mathrm{Z} \lambda \mathrm{Q} \exists \mathrm{x}_{1} \in \mathrm{D}\left[\mathrm{Z}\left(\mathrm{x}_{1}\right) \wedge \mathrm{Q}\left(\mathrm{x}_{1}\right)\right]
$$

Semantic type: $<$ et, $<$ et, $\mathrm{t}>>$

(96) is identical to the standard logical translation for a weak existential like $a$ or some in English, the only difference being that the FC wh-Determiners obligatorily trigger alternatives that need to be added to the basic meaning, while $a$ or some do not. As in the case of FC wh-words we discussed above, this process of argument-demotion may be favored by the fact that the loss of an argument in the meaning of qualunque/orice/oricare turns their denotation into a well-known semantic object type while increasing the expressive power of the language by adding to this semantic type a FC meaning dimension. (96) is also identical to the logical translation FC any in (90)c.i. Therefore, Italian and Romanian end up with FC Determiners like English, although through a more complex historical development starting with their use in FC-FRs (cf. end of Section 2.2 and fn. 11). This conclusion also connects our findings on FC-FRs with Aloni's, Chierchia's, and Farkas' earlier findings and proposals on what we labelled FC wh-Determiners in Italian and Romanian in relation to FC any in English. They were investigating first what historically came last within the family of FC wh-expressions in Italian and Romanian.

A FC-wh-word like oricat 'FC-how-much' as a full phrasal wh-word by itself or in combination with an NP or an AdjP or an AdvP differs in terms of both selectional properties and crucially domain of quantification, which must be over amounts (phrasal oricât and oricât $+\mathrm{NP}$ ) or degrees (oricât $+\mathrm{Adj} / \mathrm{AdvP})$. These intriguing issues open up areas of investigation that have received little attention so far: free choice over amounts and degrees. This limitation may be due to the focus on FC determiners like any, whose selectional properties restrict it to combine with NPs and whose quantificational force ranges over individuals only. The same limitation is found in the study of ever-FRs. The semantic treatments that have been suggested (see references at the very beginning of Section 3.1) all focus on whoever and whatever, whose semantic import—whatever it turns 
out to be-clearly affects domain of individuals. But a proper semantic treatment of ever-wh-words like however much, however much/many $+\mathrm{NP}$, and however $+\mathrm{Adj} / \mathrm{AdvP}$ requires extending the notion of free choice to amounts and degrees as well. We hope to pursue such an investigation in the future.

\section{BROADER CROSSLINGUISTIC REMARKS AND CONCLUSIONS}

We investigated a largely neglected character on the Italian and Romanian linguistic scene, namely FC-FRs. We showed that these FC-FRs are morpho-syntactically but not semantically similar to ever-FRs in English, while they are semantically similar but morpho-syntactically different from FC-any HRs in English. This indicates that Italian and Romanian can convey the same kind of FC meaning as FC-any HRs by means of different morpho-syntactic ingredients: morphologically enriched wh-words and free relative clauses rather than a determiner taking an NP (possibly modified by a headed relative clause).

The same morpho-syntactic ingredients making up FC-FRs are available in English in the very same combination in ever-FRs. Still, the result produces a different meaning in English. On the other hand, English does have a way to convey the same meaning as FC-FRs, i.e., by means of FC-any HRs. Why don't ever-FRs mean what FC-any HRs mean? Based on our analysis, the answer is that the affix -ever has a different meaning from the determiner any. One may speculate that some form of morpho-lexical blocking may prevent -ever from meaning the same as any. Italian and Romanian, lacking a non-wh FC determiner like any, do not block their affixes -unque and ori-from acquiring a FC meaning, combining with wh-words, and producing FC-FRs. Further crosslinguistic investigation of FC-FRs will hopefully lead to a better understanding of these issues.

Another consequence of our findings is that Italian and Romanian cannot convey the meaning ever-FRs convey using the same morpho-syntactic devices. As far as we can tell, both languages lack a specialized construction that conveys precisely what ever-FRs convey. A translation of There's garlic in whatever dish Bianca is cooking now in Italian and Romanian would sound roughly like: There's garlic in the dish Bianca is cooking, but I don't know what it is (assuming Bianca is cooking only one dish). A complex definite description with a headed relative clause is used, together with an overt statement of ignorance.

Both Italian and Romanian have other determiners or pronominal forms that are based on wh-words with or without morphological enrichment (see e.g. Chierchia 2013 and Zamparelli 2007 for Italian, and Farkas 2013, Grosu 2013 and Fălăuș 2015 for Romanian), but none of them can introduce free relative clauses. Only FC wh-words are allowed to introduce free relative clauses. Following our analysis, we can rephrase this observation by saying that the FC affixes in the two languages combine with wh-words without altering their morpho-syntactic properties.

The data described and analyzed in this paper further our understanding of the syntaxsemantics mapping and crosslinguistic variation among constructions derived from wh-words/phrases. Among other things, these findings show that (i) it should not be assumed that morphologically enriched wh-words introducing free relative clauses crosslinguistically will always have the semantic import of ever-FRs in English and (ii) it should not be taken for granted that the kind of free choice that is conveyed by any in English will always be conveyed by a determiner-like element across languages.

We presented various tests and scenarios to distinguish ever-FRs and FC-FRs. We also brought to light a new meaning component of $\mathrm{FC}$ constructions in episodic contexts, with FC-wh-words in Italian and Romanian and FC-any in English: their sensitivity to the 
Constraint on Acquaintance. Finally, we showed that there exists a precise and compositional connection between the core semantic properties of $\mathrm{FC}$-wh-words and the wh-words they are built on. The locus of this connection is the morphology, rather than syntax, based on the productivity of FC-wh-words within a language and across languages.

More broadly, the novel data discussed here demonstrate the necessity to further develop comparative studies of ever-FRs and FC constructions, and also illustrate the benefits of a crosslinguistic approach in bridging the gap between the two lines of research. We hope that our findings bring further support to the value of crosslinguistic semantic investigation and encourage future investigation of related constructions and different manifestations of free choice across languages.

Acknowledgements We are extremely grateful to Gennaro Chierchia, Veneeta Dayal, and Donka Farkas for their invaluable suggestions, comments, and criticism, in addition to the inspiration they provided with their own work. We would like to thank Emanuela Arosio, Andrea Beltrama, Luciano Caponigro, Gennaro Chierchia, Flavio Feniello, Onelia Rivolta, Jacopo Romoli, and Ubaldo Talarico for sharing their native intuitions and judgments about Italian, as well as Oana Draga, Donka Farkas, Ion Giurgea, Oana Lungu, and Andreea Nicolae for sharing their native intuitions and judgments about Romanian. We are also grateful to Guglielmo Cinque, Cleo Condoravdi, Daniel Kane, Gary Patterson, Carson Schütze, Harold Torrence, three anonymous reviewers, and the audiences at the Linguistics Department at Rutgers University and the Linguistics Department at the University of California Santa Cruz. Anamaria Fălăuș gratefully acknowledges funding from the Basque Government (IT769-13). We, the authors, are solely responsible for any remaining mistakes.

\section{References}

Aguilar Guevara, Ana, Maria Aloni, Angelika Port, Radek Simik, Machteld de Vos and Hedde Zeijlstra. 2010. Semantics and pragmatics of indefinites: methodology for a synchronic and diachronic corpus study. In Proceedings of the workshop Beyond semantics: Corpus-based investigations of pragmatic and discourse phenomena, eds. Stefanie Dipper and Heike Zinsmeister, 1-16. Bochum.

Aloni, Maria. 2007a. Free choice, modals and imperatives. Natural Language Semantics 15: 65-94.

Aloni, Maria. 2007b. Free choice and exhaustification: an account of subtrigging effects. In Proceedings of Sinn und Bedeutung 11, ed. Estela Puig-Waldmueller, 16-30. Barcelona: Universitat Pompeu Fabra

Aloni, Maria and Angelika Port. 2015. Epistemic indefinites and methods of identification. In Epistemic Indefinites: Exploring modality beyond the verbal domain, eds. Luis Alonso-Ovalle and Paula Menéndez-Benito, 117-140. Oxford: Oxford University Press.

Alonso-Ovalle, Luis and Paula Menéndez-Benito. 2013. Epistemic Indefinites: re we ignorant about ignorance? In Proceedings of the 19th Amsterdam Colloquium, eds. Maria Aloni, Michael Franke and Floris Roelofsen, 35-42. ILLC, University of Amsterdam.

Battye, Adrian. 1989. Free relatives, pseudo-free relatives, and the syntax of $\mathrm{CP}$ in Italian. Rivista di Linguistica 1:219-250. 
Caponigro, Ivano. 2003. Free not to ask: On the semantics of Free Relatives and wh-words cross-linguistically. Ph.D. dissertation. University of California, Los Angeles.

Caponigro, Ivano. 2004. The semantic contribution of wh-words and type shifts: Evidence from Free Relatives cross-linguistically. In Proceedings from Semantics and Linguistic Theory (SALT) XIV, ed. Robert B. Young, 38-55. Ithaca, NY: CLC Publications, Cornell University.

Caponigro, Ivano and Lisa Pearl. 2008. Silent prepositions: Evidence from free relatives. In The Syntax and Semantics of Spatial P, eds. Anna Asbury, Jakub Dotlacil, Berit Gehrke, and Rick Nouwen, 365-385. Amsterdam: Benjamins

Caponigro, Ivano and Lisa Pearl. 2009. The nominal nature of where, when, and how: Evidence from free relatives. Linguistic Inquiry 40(1): 155-164.

Chierchia, Gennaro. 2006. Broaden your views. Implicatures of domain widening and the spontaneous logicality of language. Linguistic Inquiry 37(4): 535-590.

Chierchia, Gennaro. 2013. Logic in Grammar: Polarity, free choice and intervention. Oxford: Oxford University Press.

Condoravdi, Cleo. 2015. Ignorance, indifference, and individuation with wh-ever. In Epistemic Indefinites: Exploring modality beyond the verbal domain, eds. Luis Alonso-Ovalle and Paula Menéndez-Benito, 213-243. Oxford University Press.

Cornilescu, Alexandra and Ion Giurgea. 2013. The Adjective. In A Reference Grammar of Romanian, eds. Carmen Dobrovie-Sorin and Ion Giurgea, 355-529. Amsterdam: John Benjamins.

Dayal, Veneeta. 1997. "Free relatives and ever: Identity and free choice readings." In Proceedings from Semantics and Linguistic Theory (SALT) VII, ed. Aaron Lawson, 99-116. Ithaca, NY: CLC Publications, Cornell University.

Dayal, Veneeta. 1998. Any as inherently modal. Linguistics and Philosophy 21: 433-476.

Dayal, Veneeta. 2004. The universal force of free choice any. Linguistic Variation Yearbook 4(1): 5-40.

Dayal, Veneeta. 2013a. A viability constraint on alternatives for free choice. In Alternatives in Semantics, ed. Anamaria Fălăuş, 88-122, Basingstoke: Palgrave Macmillan.

Dayal, Veneeta. 2013b. Number and (In)definiteness in FCI/Free Relatives, talk presented at the workshop 'From Grammar to Meaning: the spontaneous logicality of language', University of the Basque Country, Vitoria-Gasteiz.

Dinică, Andreea. 2012. Pronumele şi adverbele nehotărâte în limba română [Indefinite pronouns and adverbials in Romanian], PhD Dissertation, University of Bucharest.

Donati, Caterina and Carlo Cecchetto. 2011. Relabeling heads: a unified account of relativization structures. Linguistic Inquiry: 42: 519-560.

Farkas, Donka. 1985. Intensional Descriptions and the Romance Subjunctive Mood. New York: Garland Publishers.

Farkas, Donka. 1992. On the semantics of subjunctive complements. In Romance Languages and Modern Linguistic Theory, eds. Paul Hirschbühler and E.F.K. Koerner, 69-104. Amsterdam: John Benjamins.

Farkas, Donka. 2002. Extreme non-specificity in Romanian. In Romance languages and linguistic theory, eds. Claire Beyssade, Reineke Bok-Bennema, Frank Drijkoningen, and Paula Monachesi, 127-153. Amsterdam: John Benjamins.

Farkas, Donka. 2006. Free choice in Romanian. In Drawing the boundaries of meaning, eds. Betty Birner and Gregory Ward, 71-94. Amsterdam: John Benjamins. 
Farkas, Donka. 2013. The semantics of determiners. In A Reference Grammar of Romanian, eds. Carmen Dobrovie-Sorin and Ion Giurgea, 175-230. Amsterdam: John Benjamins.

Fălăuş, Anamaria. 2015. Romanian epistemic indefinites. In Epistemic Indefinites: Exploring modality beyond the verbal domain, eds. Luis Alonso-Ovalle and Paula Menéndez-Benito, 60-81. Oxford: Oxford University Press.

von Fintel, Kai. 2000. Whatever. In Proceedings from Semantics and Linguistic Theory (SALT) X, eds. Brendan Jackson and Tanya Matthews, 27-39. Ithaca, NY: CLC Publications, Cornell University.

Gheorghe, Mihaela. 2014. Free relative clauses with quantificational reading in old Romanian. In Proceedings of the International Conference Globalization, Intercultural Dialogue and National Identity: Language and Discourse, 17-22.

Giannakidou, Anastasia. 2001. The Meaning of Free Choice. Linguistics and Philosophy 24: 659-735.

Giannakidou, Anastasia and Lisa Lai-Shen Cheng. 2006. (In)Definiteness, Polarity, and the Role of wh-morphology in Free Choice. Journal of Semantics 23: 135-183.

Giurgea, Ion. 2016. The Romanian interrogative particle oare, in a comparative and historical perspective, manuscript, "Iorgu Iordan-Al. Rosetti" Institute of Linguistics.

Givón, Talmy. 2011. Ute Reference Grammar. Amsterdam: John Benjamins.

Grosu, Alexander. 2013. Relative Clause Constructions and unbounded dependencies. In A Reference Grammar of Romanian, eds. Carmen Dobrovie-Sorin and Ion Giurgea, 597-662. Amsterdam: John Benjamins.

Heller Daphna and Lynsey Wolter. 2011. On identification and transworld identity in natural language: the case of -ever free relatives. Linguistics and Philosophy 34(2):169-199.

Horn, Laurence. 1989. A Natural History of Negation, Chicago: University of Chicago Press. Reissued, Stanford, CA: CSLI Publications, 2001.

Horn, Laurence. 2000. Any and ever: Free Choice and Free Relatives. In Proceedings of the 15th Annual Conference of the Israeli Association for Theoretical Linguistics, ed. Adam Wyner, 71-111.

Horn, Laurence. 2005. Airport '86 Revisited: Toward a unified indefinite any. In The Partee Effect, eds. Gregory Carlson and Francis J. Pelletier, 179-205. CSLI. Stanford.

Izvorski, Roumyana. 2000. Free adjunct free relatives. In Proceedings of WCCFL 19, 232-245. Somerville: Cascadilla Press.

Jacobson, Pauline. 1995. On the quantificational force of English free relatives. In Quantification in natural languages, eds. Elke Bach, Elfriede Jelinek, Angelika Kratzer and Barbara Partee, 451-486. Dordrecht: Kluwer.

Jayez, Jacques and Lucia Tovena. 2005. Free-choiceness and Non Individuation. Linguistics and Philosophy 28: 1-71.

Jayez, Jacques and Lucia Tovena. 2006. Epistemic Determiners. Journal of Semantics 23: 217-50.

Kadmon, Nirit and Fred Landman. 1993. Any. Linguistics and Philosophy 16: 353-422.

Legrand, Jean. 1975. Or and Any: the Semantics and Syntax of Two Logical Operators, $\mathrm{Ph} . \mathrm{D}$. dissertation, University of Chicago.

Matthewson, Lisa, Henry Davis and Hotze Rullmann. 2007. Evidentials as epistemic modals: Evidence from St'át'imcets. The Linguistic Variation Yearbook 7:201-254. 
Menéndez-Benito, Paula. 2005. The grammar of choice. Ph.D. Dissertation, University of Massachusetts, Amherst.

Menéndez-Benito, Paula. 2010. On Universal Free Choice Items. Natural Language Semantics 18: 33-64.

Montague, Richard. 1973. The proper treatment of quantification in Ordinary English. In Jaakko Hintikka, Julius Moravcsik, Patrick Suppes (eds.), Approaches to Natural Language, 221-242, Dordrecht.

Patterson, Gary and Ivano. Caponigro. 2016. The puzzling degraded status of who free relative clauses in English. English Language and Linguistics 20(2): 341-352.

Polinsky, Maria. 2015. Tsez Syntax: A Description, manuscript, Harvard University.

Rawlins, Kyle. 2013. (Un)conditionals. Natural Language Semantics 21(2): 111-178.

Reichenbach, Hans. 1947. Elements of symbolic logic. New York: The Free Press.

van Riemsdijk, Henk. 2006. Free relatives. The Blackwell companion to syntax, Vol. 2, eds. Martin Everaert and Henk van Riemsdijk, 338-382, Blackwell.

Rizzi, Luigi. 1984. Spiegazione e teoria grammaticale. Padova: C.L.E.S.P.

Sæbø, Kjell Johan. 2001. The semantics of Scandinavian free choice items. Linguistics and Philosophy 24(6): 737-788.

Zamparelli, Roberto. 2007. On singular existential quantifiers in Italian. In Existence: Semantics and Syntax, eds. Ileana Comorovski and Klaus von Heusinger, 293-328. Berlin: Springer. 